\title{
Estudo comparativo entre válvulas biológicas e válvulas mecânicas nas posiçôes mitral ou aórtica até 14 anos
}

Domingo M. BRAILE*, Roberto V. ARDITO*, Marcos ZAIANTCHICK*, José L. Verde SANTOS*, Nelson L. K. L. CAMPOS*, José Luiz B. JACOB*, Dorotéia R. S. SOUZA*, Walter RADE*, Maria Inês MARTINS*, Adalberto M. LORGA*

BRAILE, D. M.; ARDITO, R. V.; ZAIANTCHICK, M.; SANTOS, J. L. V.; CAMPOS, N. L. K. L.; JACOB, J. L. B.; SOUZA, D. R. S.; RADE, W.; MARTINS, J. I.; LORGA, A. M. - Estudo comparativo entre válvulas biológicas e válvulas mecâcnicas nas posições mitral ou aórtica até 14 anos. Rev. Bras. Cir. Cardiovasc., 3(3): 141-158, 1988.

RESUMO: Foram estudados 1222 pacientes, submetidos a troca valvar simples, sendo 652 mitrais (Mi) e 570 aórticas (Ao). Os pacientes foram classificados por sexo, idade e etiologia. No grupo Mi. receberam 126 próteses mecânicas, como segue: 49 Björk-Shiley (B-S); 71 Lillehei-Kaster (L-K); 6 Hall-Kaster $(\mathrm{H}-\mathrm{K})$ e 526 próteses de pericárdio bovino IMC (PBIMC). O seguimento pós-operatório foi de $95 \%$ a $100 \%$. A mortalidade hospitalar foi de $21 \%$ para a L-K e $9,5 \%$ para a PBIMC. A incidência de trombose e tromboembolismos em eventos por $100 \%$ pacientes-ano foi de 7,$7 ; 5,6 ; 6,7$ e 1,0 para: B-S, L-K, H-K e PBIMC, respectivamente. A incidência de calcificaçāo e roturas foi de 1,8 por 100 pacientes-ano para a PBIMC, e não ocorreu nas próteses mecânicas. Somente os pạcientes com próteses mecânicas foram anticoagulados. O grupo Ao totalizou 336 próteses mecânicas (92 B-S, 111 L-K, 133 H-K) e 234 PBIMC. O seguimento pós-operatório foi de $97 \%$ a $100 \%$. A mortalidade hospitalar foi de $5,5 \%$ para o grupo das mecânicas e 2,6\% para o das biológicas. A incidência de trombose e tromboembolismo em eventos por 100 pacientes-ano foi de 3,0 para B-S, 2-3 para L-K, 2,5 para $\mathrm{H}-\mathrm{K}$ e 0,3 para PBIMC. Calcificaçāo, roturas e falhas mecânicas foram de 0,54 eventos por 100 pacientes-ano para PBIMC e de 0,38 eventos por 100 pacientes-ano para H-K. No grupo mecânico, os pacientes receberam aspirina e dipiridamol e $30 \%$ receberam anticoagulante oral. Os autores concluíram que a sobrevida, de um modo geral, nāo está relacionada ao tipo de prótese empregada. A incidência de trombose e tromboembolismo é mais elevada com válvulas mecânicas, e a taxa de complicaçōes é mais baixa com válvulas biológicas. A anticoagulação oral é obrigatória para as próteses mecânicas na posição Mi, mas não é essencial na posição Ao. As biopróteses não necessitam de anticoagulantes. Por estes motivos, os autores empregam, de rotina, próteses mecânicas para a posição Ao, a menos que existam contra-indicações, e biopróteses para a posição Mi.

DESCRITORES: próteses valvulares cardiacas, biológicas; próteses valvulares cardiacas, mecânicas; próteses valvulares cardiacas, cirurgia; valva mitral, cirurgia; valva aórtica, cirurgia.

\section{INTRODUÇĀO}

É evidente que seria desejo de todo cirurgião praticar, sempre, uma valvoplastia, tentando reparar o que a natureza alterou. Porém, muitas vezes, a valva se encontra num estágio crítico tal, que é impossivel preservá-la; daí a necessidade de trocá-la. Por outro lado, graças ao avanço da tecnologia e da busca incessante dos

Trabalho realizado no Instituto de Moléstias Cardiovasculares. São José do Rio Preto, SP, Brasil.

Apresentado ao 15: Congresso Nacional de Cirurgia Cardiaca. Rio de Janeiro, 7 e 8 de abril de 1988.

- Do Instituto de Moléstias Cardiovasculares de São José do Rio Preto.

Endereço para separatas: Domingo M. Braile. Rua Castele D'Água, 3030. 15015 São José do Rio Preto, SP, Brasil. 
BRAILE, D. M.; ARDITO, R. V.; ZAIANTCHICK, M.; SANTOS, J. L. V.; CAMPOS, N. L. K. L.; JACOB, J. L. B.; SOUZA, D. R. S.; RADE, W.; MARTINS, J. I.; LORGA, A. M. - Estudo comparativo entre válvulas biológicas e válvulas mecâcnicas nas posiçōes mitral ou aórtica até 14 anos. Rev. Bras. Cir. Cardiovasc., 3(3): 141-158, 1988.

pesquisadores, existem, hoje, várias opções que permitem melhorar as condiçōes de vida do paciente que necessita ter suas valvas substituidas. De um lado, estāo as válvulas mecânicas, que, no início dos anos 60 , tiveram, com HARKEN et alii ${ }^{16}$ e STARR \& EDWARDS ${ }^{42}$ seu primeiro sucesso; e, de outro, as válvulas biológicas introduzidas por ROSS ${ }^{35}$ e BARRAT-BOYES ${ }^{2}$ com ho- $^{-}$ moenxertos aórticos.

Contudo, desde o princípio, os riscos de tromboembolismo e o uso de anticoagulantes associados às válvulas mecânicas e a durabilidade nāo comprovada das próteses biológicas são razōes freqüentemente citadas para se optar por um ou outro tipo de prótese.

Diante da evolução das próteses no início dos anos 70 , as válvulas mecânicas foram associadas a uma baixa incidência de tromboembolismo e se tornaram duráveis, sendo, contudo, indispensável o uso de anticoagulantes, com o risco de sangramento $3,9,11,28,29,32,33,41$.

O outro grande problema que acompanha as próteses mecânicas é a formação de pannus, decorrente dos processos de cicatrização, que ocorre a longo prazo, impedindo o movimento do sistema oclusor. As biopróteses, por sua vez, melhoraram, também, sua durabilidade, porém ainda estāo expostas a calcificação e rotu$\mathrm{ra}^{5}, 6,12,13,14,19,21,23,26,34,36-39$.

É interessante destacar que, entre os 2 tipos de próteses valvulares, as biopróteses apresentam um comportamento mais uniforme, degradando-se ao longo do tempo de forma lenta, sendo raros os casos em que se exige uma cirurgia de emergência. Por outro lado, para as próteses mecânicas, os casos são severamente agudos com o travamento do movimento das partes móveis, com a necessidade de intervenção imediata e mortalidade operatória alta. Outras vezes, a troca de uma prótese mecânica embolígena é indicada com o paciente já incapacitado para a vida, por ter sofrido um acidente vascular cerebral de grandes proporçōes. Quando o paciente é portador de uma prótese biológica, é possivel seguí-lo na sua evoluçāo clínica. Mesmo diante da troca da bioprótese por calcificaçāo, a cirurgia pode ser progra- mada convenientemente e é acompanhada de baixa mortalidade.

O objetivo deste trabalho é comparar o desempenho de diferentes tipos de válvulas mecânicas com as próteses valvulares de pericárdio bovino IMC-Biomédica, em posiçōes mitral ou aórtica.

\section{MATERIAL E MÉTODOS}

Através de análise prospectiva, foram analisados, evolutivamente, 1222 pacientes, sendo 640 do sexo masculino e 582 do sexo feminino, com uma faixa etária de 5 a 72 anos, nos quais foram implantadas 462 próteses mecânicas: (141 Björk-Shiley (B-S), 182 Lillehei-Kaster (L-K), 139 Hall-Kaster (H-K) e 760 biopróteses IMCBiomédica (PBIMC). Na posiçāo aórtica, foram implantadas 92 B-S, 111 L-K, 133 H-K e 234 biopróteses. Na posição mitral 49 B-S, 71 L-K, 6 H-K e 526 PBIMC, isoladamente, no período de dezembro de 1973 a agosto de 1987, no Instituto de Moléstias Cardiovasculares (IMC) de São José do Rio Preto.

As etiologias responsáveis pelas lesōes valvares levando à sua substituição foram: doença reumática, degeneraçāo mixomatosa, endocardite bacteriana, valvopatia congênita, esclerose e outras (Tabela 1).

A via de acesso utilizada para a substituição valvar mitral foi a toracotomia anterior direita até 1977 e, posteriormente, a esternotomia mediana. A via de acesso para a substituição aórtica foi, sempre, a esternotomia mediana. A cirurgia foi realizada através de circulação extracorpórea tipo cava-cava, com perfusão pela aorta ou artéria femoral e hipotermia moderada $\left(28^{\circ} \mathrm{C}\right)$. Após a infusão de solução cardioplégica na raiz da aorta, obteve-se parada cardiaca em diástole com temperatura miocárdica em torno de $6^{\circ} \mathrm{C}$. A aorta foi aberta transversalmente (ou o átrio esquerdo), a valva lesada foi retirada e passados pontos de Mersilene 2-0 em "U" verdadeiro para o implante da bioprótese e em " $U$ " invertido para a prótese mecânica em ambas as posiçōes. Implantada a próte-

TABELA 1

NÚMERO DE PRÓTESES MECANICAS OU BIOLÓGICAS IMPLANTADAS EM POSIÇÃO AÓRTICA OU MITRAL

\begin{tabular}{|c|c|c|c|c|c|c|c|c|c|c|}
\hline \multirow{2}{*}{ POSıÇÃo } & \multicolumn{2}{|c|}{ PB IMC } & \multicolumn{2}{|c|}{ B-S } & \multicolumn{2}{|c|}{$\mathrm{H}-\mathrm{K}$} & \multicolumn{2}{|c|}{$L-K$} & \multirow{2}{*}{ TOTAL } & \multirow{2}{*}{$\%$} \\
\hline & $\bar{T}$ & $\%$ & $\bar{T}$ & 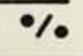 & $T$ & $\%$ & $\bar{T}$ & $\%$ & & \\
\hline AÓRTICA & 234 & 19,1 & 92 & 7,5 & 133 & 10,9 & 111 & 9,1 & 570 & 46,6 \\
\hline MITRAL & 526 & 43,0 & 49 & 4,0 & 6 & 0,5 & 71 & 5,8 & 652 & 53,4 \\
\hline TOTAL & 760 & 62,1 & 141 & 11,5 & 139 & 11,4 & 182 & 14,9 & 1222 & 100,0 \\
\hline
\end{tabular}

PB IMC = PRÓTESE BIOLÓGICA DE PERICÁRDIO BOVINO IMC-BIOMÉDICA ; B-S = BJORK - SHILEY;H-K = HALL KASTER ; L-K = LILLEHEI - KASTER ; $T=$ TOTAL. 
BRAILE, D. M.; ARDITO, R. V.; ZAIANTCHICK, M.; SANTOS, J. L. V.; CAMPOS, N. L. K. L.; JACOB, J. L. B.; SOUZA, D. R. S.; RADE, W.; MARTINS, J. I.; LORGA, A. M. - Estudo comparativo entre válvulas biológicas e válvulas mecâcnicas nas posiçōes mitral ou aórtica até 14 anos. Rev. Bras. Cir. Cardiovasc., 3(3): 141-158, 1988.

se escolhida, a aorta (ou o átrio esquerdo) foi suturada com fios de Prolene e feita a saída da circulação extracorpórea (CEC) após a reperfusão com sangue modificado. Posteriormente, o paciente foi levado para a UTI, permanecendo ai durante 48 horas, quando teve alta para 0 quarto, onde permaneceu por mais 6 dias, recebendo alta no 8 : dia de pós-operatório.

O seguimento dos pacientes e das próteses foi feito através de ecocardiografia bidimensional no pré-operatório, no 4 : dia de pós-operatório, no 30 : dia, no 6: mês e a cada ano, juntamente como acompanhamento clínico e laboratorial.

Os pacientes portadores de prótese mecânica em posição mitral receberam alta hospitalar fazendo, sempre, uso de anticoagulante oral e, em alguns casos, aspirina e dipiridamol. Os portadores de prótese mecânica em posiçāo aórtica receberam alta com o uso de aspirina e dipiridamol (e anticoagulantes orais) em casos selecionados. Os pacientes com bioprótese receberam alta com aspirina e dipiradamol, somente.

O seguimento a longo prazo foi feito com especial atenção para as complicaçōes: calcificação, rotura, falha mecânica, endocardite, trombose, tromboembolismo e vazamento paravalvular. Foram feitas curvas atuariais de sobrevida dos pacientes e das próteses, além da análise das complicaçōes tardias fatais e não fatais.

Todos os dados foram coletados por um sistema de processamento computadorizado com software desenvolvido no próprio Serviço, que permite acesso permanente às informações e confecção das curvas de sobrevida dos pacientes e análise das complicaçōes, assim como os dados estatísticos pertinentes. O sistema de computação empregado é o PC IBM.

\section{RESULTADOS}

\section{Próteses mecânicas em posição mitral}

Foram instaladas em posição mitral 49 próteses tipo Björk-Shiley (Tabela 1), em pacientes cujas idades varia- ram de 11 a 52 anos, com média de 31 anos, sendo $30,6 \%$ do sexo masculino e $69,4 \%$ do sexo feminino. Em $48(97,9 \%)$ pacientes, a doença reumática foi a etiologia mais freqüentemente responsável pela disfunção valvar encontrada neste grupo (Tabela 2). A mortalidade hospitalar foi igual a $17,4 \%$, sendo que, em $75,0 \%$ dos casos, a insuficiência ventricular esquerda foi o fator determinante (Tabela 3 ). Trinta e oito pacientes foram acompanhados por período de 14 anos, com média de seguimento igual a 6,5 anos (Tabela 5). A curva extraida de tal estudo revelou uma taxa de sobrevida de $55,0 \%$ ao final de 14 anos (Gráfico 1). A causa de mortalidade tardia mais freqüente, de acordo com a análise, foi a insuficiência cardiaca, com uma taxa de $25,0 \%$ dos óbitos ocorridos neste periodo (Tabela 4). A reoperação foi necessária em 24 (52,2\%) pacientes. Com a utilização da prótese B-S em posição mitral, a ocorrência de trombos e tromboembolismo foi igual a 7,7 eventos por 100 pacientes-ano (Tabela 5).

$\mathrm{Na}$ amostra estudada, 71 pacientes foram submetidos ao implante de prótese Lillehei-Kaster nesta topografia (Tabela 1), sendo $31,0 \%$ do sexo masculino e $69,0 \%$ do sexo feminino, com idades entre 6 a 77 anos e idade média de 36 anos. Destes pacientes, 66 foram acompanhados por um tempo médio de 6,7 anos, durante 373 pacientes-ano (Tabela 5). Entre eles, a etiologia mais freqüente foi a doença reumática (Tabela 2). A taxa de mortalidade hospitalar foi de $21,1 \%$ sendo que, em $86,6 \%$ dos casos, se deveu a insuficiência ventricular esquerda (Tabela 3 ). A curva de sobrevida revelou que $40,0 \%$ dos pacientes achavam-se vivos ao final de um período de 14 anos (Gráfico 1). Em 42,0\% dos casos, os pacientes encontravam-se livres de complicaçōes após tal período (Gráfico 2). A causa da mortalidade tardia mais incidente foi a trombose de prótese, com valores de 45,6 do total de óbitos observados (Tabela 4). A incidência de trombose e tromboembolismo, neste grupo de pacientes, foi igual a 5,6 eventos por 110 pacientes-ano (Tabela 5 ). Além disso, $16,9 \%$ dos pacientes necessitaram de reintervençōes cirúrgicas, durante o seu acompanhamento.

TABELA 2

INCIDEANCIA DAS ETIOLOGIAS RESPONSÁVEIS PELAS DISFUNCÓES VALVARES EO TIPO DE PROTESE EMPREGADO PARA SUAS CORRECÓES

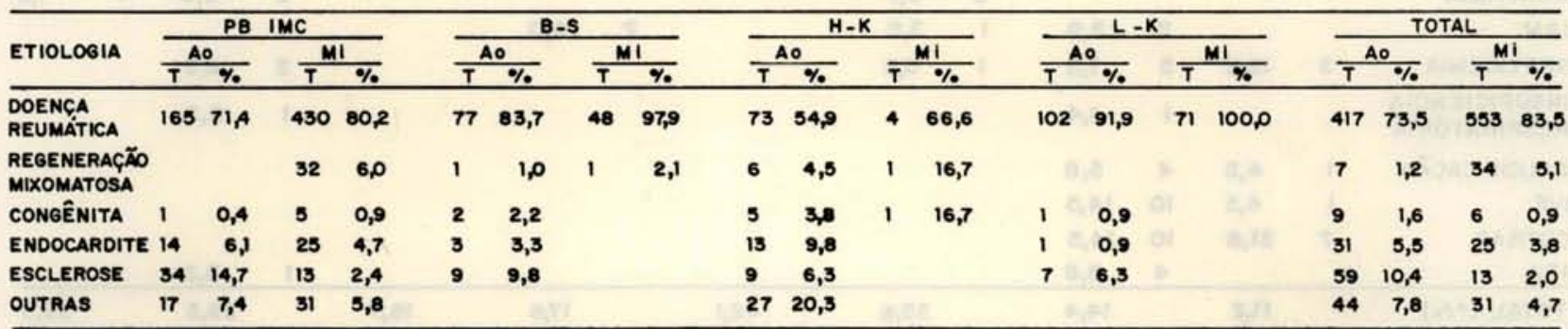

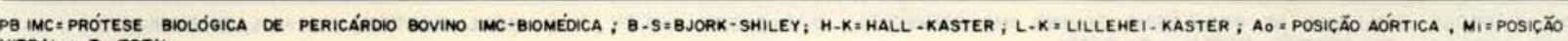
MITRAL; $T=$ TOTAL 
BRAILE, D. M.; ARDITO, R. V.; ZAIANTCHICK, M.; SANTOS, J. L. V.; CAMPOS, N. L. K. L.; JACOB, J. L. B.; SOUZA, D. R. S.; RADE, W.; MARTINS, J. I.; LORGA, A. M. - Estudo comparativo entre válvulas biológicas e válvulas mecâcnicas nas posiçōes mitral ou aórtica até 14 anos. Rev. Bras. Cir. Cardiovasc., 3(3): 141-158, 1988.

TABELA 3 CAUSAS DE MORTALIDADE HOSPITALAR EM PACIENTES COM PRÓTESES EM POSIÇÃO AORTICA OU MITRAL

\begin{tabular}{|c|c|c|c|c|c|c|c|c|c|c|c|c|c|c|c|c|}
\hline \multirow{3}{*}{ CAUSAS } & \multicolumn{4}{|c|}{ PB IMC } & \multicolumn{4}{|c|}{ B-S } & \multirow{2}{*}{\multicolumn{4}{|c|}{ Ao $\quad$ H-K }} & \multicolumn{4}{|c|}{$L-K$} \\
\hline & \multicolumn{2}{|c|}{ Ao } & \multicolumn{2}{|c|}{ Mi } & \multicolumn{2}{|c|}{$\Delta 0$} & \multicolumn{2}{|c|}{$\mathrm{MI}$} & AO & & Mi & & \multicolumn{2}{|r|}{ Ao } & \multicolumn{2}{|c|}{$\mathrm{Mi}$} \\
\hline & $\bar{T}$ & $\bullet$ & $\bar{T}$ & $\%$ & $T$ & $x_{0}$ & $T$ & $\%$ & $T$ & $\%$ & $\bar{T}$ & $\%$ & $\bar{T}$ & $\bullet$ & $\mathbf{T}$ & $\bullet$ \\
\hline $\begin{array}{l}\text { TAMPONAMENTO } \\
\text { CARDIACO }\end{array}$ & 1 & 20,0 & 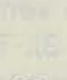 & & & & & & & & & & & & & \\
\hline IVE & 1 & 20,0 & 21 & 42,0 & 1 & 20,0 & 6 & 75,0 & 3 & 42,9 & & & 4 & 66,6 & 13 & 86,6 \\
\hline ENDOCARDITE & & & 3 & 6,0 & & & & & 1 & 14,3 & & & & & & \\
\hline IAM & 12) & 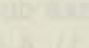 & 1 & 2,0 & a & $x^{2}$ & (2) & & 1 & 14,3 & & & & & & \\
\hline $\begin{array}{l}\text { ANEURISMA } \\
\text { DE AORTA }\end{array}$ & 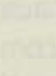 & $\sqrt{4}+10$ & 17 & 1) & ant & $\sqrt{n+10}$ & & & 1 & 14,3 & & & & & & \\
\hline $\begin{array}{l}\text { STONE HEART } \\
\text { AVC }\end{array}$ & t & & 7 & 14,0 & 2 & 40,0 & & & 1 & 14,3 & & & & & & \\
\hline HEMORRAGIA & 1 & 20,0 & 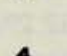 & 8,0 & r & & & & & & & & 1 & 16,7 & & \\
\hline $\begin{array}{l}\text { COAGULOPATIA } \\
\text { IRA }\end{array}$ & 2 & 40,0 & $\begin{array}{l}4 \\
2\end{array}$ & $\begin{array}{l}8,0 \\
4,0\end{array}$ & 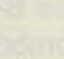 & & & & y & 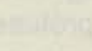 & . & 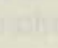 & $\sqrt{n}$ & & 35 & \\
\hline IRA & & & 5 & 100 & 1 & 20,0 & & & & & & & & & & \\
\hline $\begin{array}{l}\text { INSUFICIÊNCIA } \\
\text { RESPIRATÓRIA }\end{array}$ & & & 1 & 2,0 & 1 & 20,0 & & & & & & & & & & \\
\hline $\begin{array}{l}\text { ROTURA } \\
\text { VENTRICULAR }\end{array}$ & & & 2,0 & 4,0 & & & & & & & & 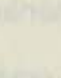 & F & & $x$ & 64 \\
\hline $\begin{array}{l}\text { TROMBOSE DE } \\
\text { PRÓTESE }\end{array}$ & & & & & & & 1 & 12,5 & & & & & & & 1 & 6,7 \\
\hline ARRITMIA & & & 4 & 8,0 & & & & & & & & & 1 & 16,7 & 1 & 6,7 \\
\hline $\begin{array}{l}\text { EMBOLIA } \\
\text { PULMONAR }\end{array}$ & 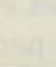 & & & & 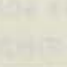 & & 1 & 12,5 & & & & & & & & \\
\hline TOTAL & 5 & 26,0 & 50 & 9,5 & 5 & 5,4 & 8 & 17,4 & 7 & 5,3 & & & 6 & 5,4 & 15 & 21,1 \\
\hline
\end{tabular}

PB, IMC = PRÓTESE BIOLÓGICA DE PERICÁROIO BOVINO IMC-BIOMÉOICA ; B-S=BJORK -SHILEY; H -K = HALL-KASTER ; L-K = LILLEHI - KASTER; AO=POSIÇĂO AORTICA ; MI=POSIÇÃO MITRAL ; T=TOTAL.

TABELA 4

CAUSAS DE MORTALIDADE TARDIA EM PACIENTES COM PRÓTESES MECANICAS OU BIOLOGICAS EM POSICÃO AÓRTICA OU MITRAL

\begin{tabular}{|c|c|c|c|c|c|c|c|c|c|c|c|c|c|c|c|c|c|}
\hline \multirow{3}{*}{ CAUSAS } & \multicolumn{4}{|c|}{ PB IMC } & \multicolumn{4}{|c|}{ B-S } & \multicolumn{5}{|c|}{$\mathrm{H}-\mathrm{K}$} & \multicolumn{4}{|c|}{$L-K$} \\
\hline & \multicolumn{2}{|c|}{ Ao } & \multicolumn{2}{|c|}{$\mathrm{MI}$} & \multicolumn{2}{|c|}{ Ao } & \multicolumn{2}{|r|}{ Mi } & & \multicolumn{2}{|c|}{ Ao } & \multicolumn{2}{|r|}{$\mathrm{Mi}$} & \multicolumn{2}{|r|}{ Ao } & \multicolumn{2}{|c|}{$\mathrm{Mi}$} \\
\hline & $T$ & $\%$ & $T$ & $\%$ & $T$ & $\%$ & $T$ & $\%$ & & $T$ & $\%$ & $T$ & $\%_{0}$ & $T$ & $\%$ & $T$ & $\%$ \\
\hline $\begin{array}{l}\text { INSUF!CIENCIA } \\
\text { CARDIACA }\end{array}$ & 1 & 4,5 & 3 & 4,4 & 4 & 12,9 & 4 & 25,0 & & 2 & 9,0 & & & 3 & 9,9 & 7 & 31,8 \\
\hline $\begin{array}{l}\text { TROMBOSE DE } \\
\text { PRÓTESE }\end{array}$ & & & & & 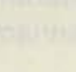 & & 7 & 43,8 & & 6 & 27,4 & & & 6 & 19,3 & 10 & 45,6 \\
\hline AVC & 1 & 4,5 & 6 & 8,7 & 1 & 3,2 & 1 & 620 & & 1 & 4,6 & & & 5 & 16,3 & 1 & 4,6 \\
\hline ENDOCARDITE & 4 & 18,1 & 9 & 13,0 & & & 2 & 12,5 & & 3 & 13,7 & 1 & 100,0 & 2 & 6,3 & & \\
\hline MORTE SÚBITA & 3 & 13,6 & 15 & 21,7 & 6 & 19,3 & 2 & 12,5 & & 83 & 36,4 & & & 9 & 29,3 & 3 & 13,7 \\
\hline ARRITIMIA & & & & & 3 & 9,7 & & & & & & & & 2 & 6,3 & 1 & 4,6 \\
\hline IAM & & & 2 & 2,9 & 1 & 3,2 & 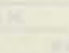 & & & 2 & 9,0 & & & tat & & & \\
\hline SEPTICEMIA & 3 & 13,6 & 5 & 7,3 & 1 & 3,2 & $3=$ & $\sqrt{7}$ & 2.12 & & $2 y$ & 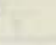 & 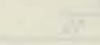 & 2 & 6,3 & & \\
\hline $\begin{array}{l}\text { INSUFICIÊNCIA } \\
\text { RESPIRATÓRIA }\end{array}$ & 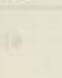 & . & 1 & 1,4 & $x$ & 12 & was & 34 & 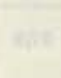 & (1) & in & t & $x 6$ & 1 & 3,2 & & \\
\hline CALCIFICACĀOO & 1 & 4,5 & 4 & 5,8 & $y=$ & 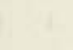 & $4 x^{4}$ & 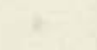 & 48 & & 64 & tet & $8=$ & $y=$ & & & \\
\hline IVE & 1 & 4,5 & 10 & 14,5 & xall & 11 & ays & ₹ & & & 3 & A & 670 & 8 & 30 & & \\
\hline OUTRAS & 7 & 31,8 & 10 & 14,5 & & & an & 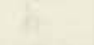 & & & ax & 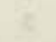 & $9 x$ & 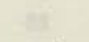 & & . & 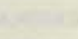 \\
\hline IRA & 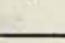 & & 4 & 5,8 & & & 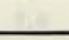 & - & & & 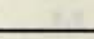 & - & t & 1 & 3,2 & & \\
\hline TOTAL $(\bullet / \bullet)$ & & 11,2 & & 14,4 & & 35,6 & 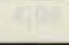 & 42,1 & & & 17,6 & & 16,7 & 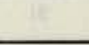 & 29,5 & & 39,3 \\
\hline
\end{tabular}

PQ IMC = PRÓTESE BIOLÓGICA DE PERICÁRDIO BOVINO IMC -BIOMÉDICA ; B-S = BJORK - SHILEY; H-K = HALL - KASTER ; L-K=LILLEHEI - KASTER ; AO = POSIÇÃO AORTICA; MI= POSIÇÄO MITRAL; $T=$ TOTAL. 
BRAILE, D. M.; ARDITO, R. V.; ZAIANTCHICK, M.; SANTOS, J. L. V.; CAMPOS, N. L. K. L.; JACOB, J. L. B.; SOUZA, D. R. S.; RADE, W.; MARTINS, J. I.; LORGA, A. M. - Estudo comparativo entre válvulas biológicas e válvulas mecâcnicas nas posiçōes mitral ou aórtica até 14 anos. Rev. Bras. Cir. Cardiovasc., 3(3): 141-158, 1988.

TABELA 5

CORRELAÇÃO ENTRE O TEMPO DE SEGUIMENTO DE PACIENTES COM PROTESES MECANICAS EM POSIÇÃO AORTICA OU MITRAL E O INDICE DE EVENTOS \% PACIENTE-ANO

\begin{tabular}{|c|c|c|c|c|c|c|}
\hline \multirow{2}{*}{ POSıÇÃo } & \multirow{2}{*}{ PRÓTESE } & \multicolumn{2}{|c|}{ ANOS SEGUIMENTO } & \multirow{2}{*}{ ANOS/PACIENTE } & \multicolumn{2}{|c|}{ EVENTO \% PACIENTE - ANO } \\
\hline & & LIMITE & TEMPO MÉDIO & & $\begin{array}{l}\text { TROMBOSE/ } \\
\text { TROMBOEMBOLISMO }\end{array}$ & $\begin{array}{l}\text { CALCIFICAÇÃO/ } \\
\text { ROTURA }\end{array}$ \\
\hline \multirow[t]{4}{*}{ AÓRTICA } & $L-K$ & $6-14$ & 7,5 & 784,8 & 2,3 & \\
\hline & B-s & $7-12$ & 7,1 & 616,4 & 3,0 & \\
\hline & $\mathbf{H}-\mathbf{K}$ & $1-7$ & 4,2 & 522,4 & 2,5 & 0,4 \\
\hline & PB IMC & $1-7$ & 1,9 & 370,0 & 0,3 & 0,5 \\
\hline \multirow[t]{4}{*}{ MITRAL } & $L-K$ & $6-14$ & 6,7 & 373,6 & 5,6 & \\
\hline & B-s & $8-14$ & 6,5 & 246,3 & 7,7 & \\
\hline & $H-K$ & $2-5$ & 2,5 & 14,8 & 6,8 & \\
\hline & PB IMC & $1-9$ & 3,1 & 1484,0 & 1,0 & 1,8 \\
\hline
\end{tabular}

L-K= LILLEHEI - KASTER; B-S=BJORK - SHILEY ; H-K = HALL-KASTER ; PB IMC = PRÓTESE BIOLÓGICA DE PERICÁRDIO BOVINO IMC-BIOMÉDICA

GRÁFICO 1

CURVAS ATUARIAIS DE SOBREVIDA DE PACIENTES COM PRÓTESES EM POSIÇÃO MITRAL

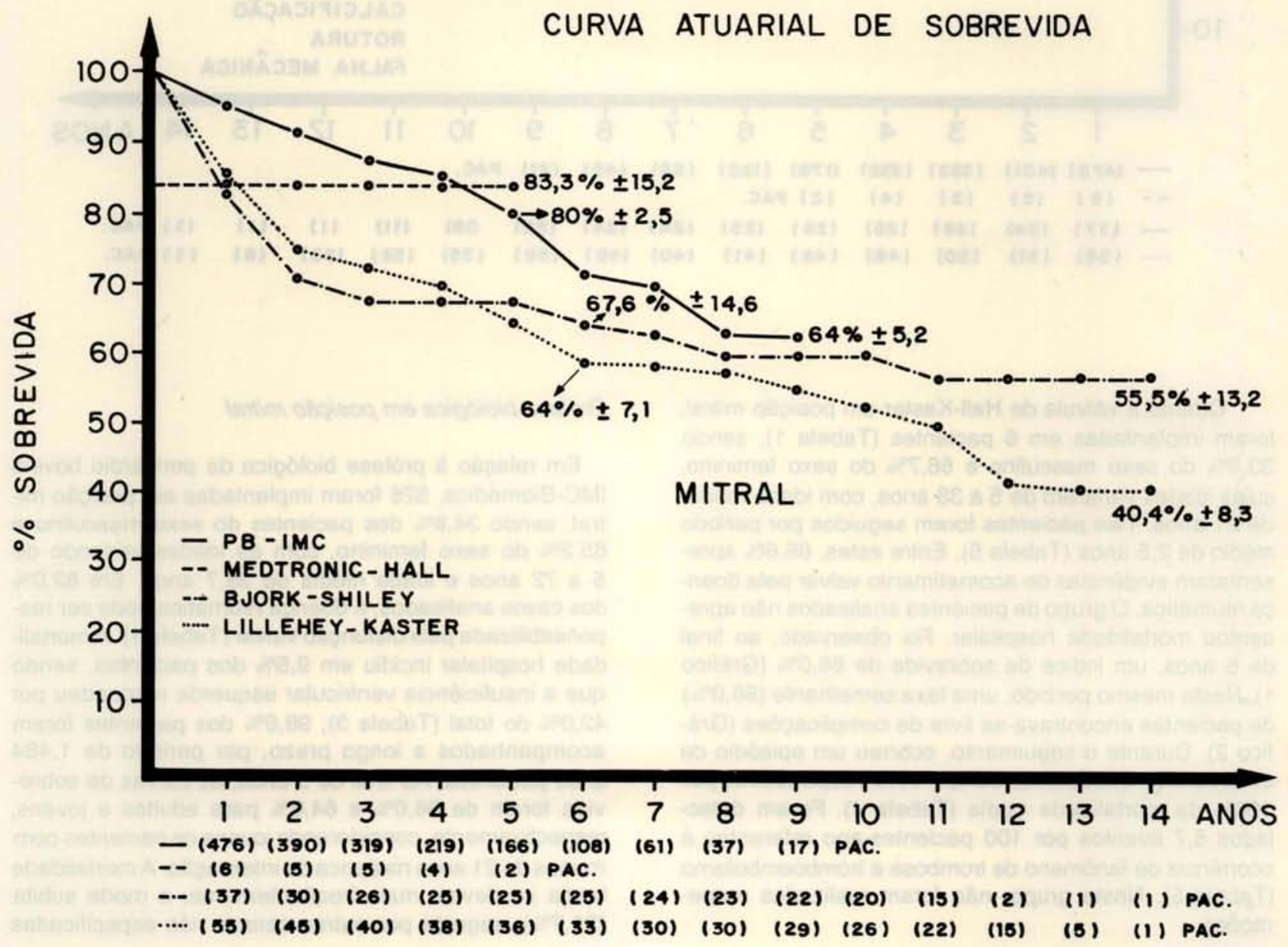


BRAILE, D. M.; ARDITO, R. V.; ZAIANTCHICK, M.; SANTOS, J. L. V.; CAMPOS, N. L. K. L.; JACOB, J. L. B.; SOUZA, D. R. S.; RADE, W.; MARTINS, J. I.; LORGA, A. M. - Estudo comparativo entre válvulas biológicas e válvulas mecâcnicas nas posiçōes mitral ou aórtica até 14 anos. Rev. Bras. Cir. Cardiovasc., 3(3): 141-158, 1988.

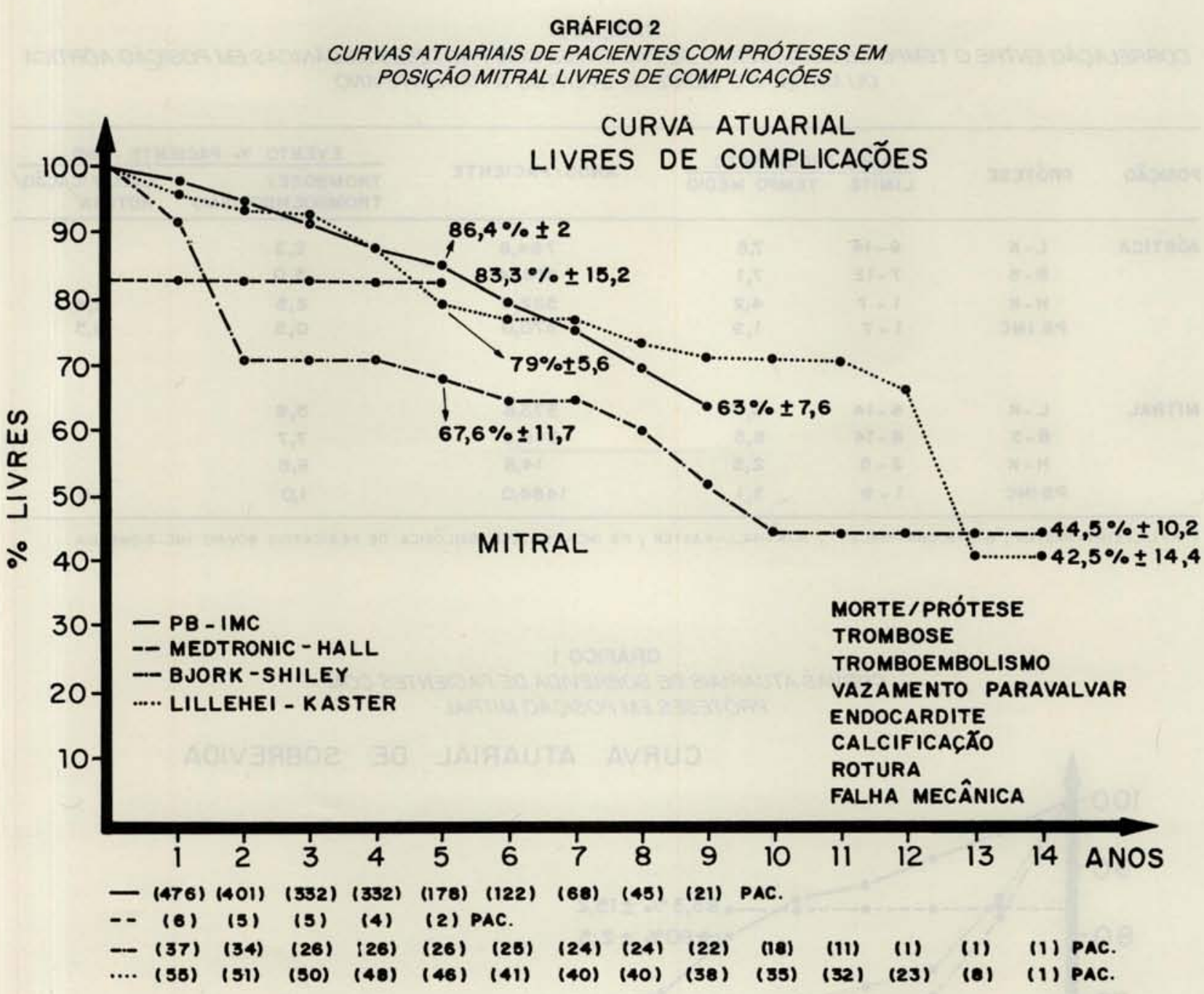

Quanto à válvula de Hall-Kaster em posição mitral, foram implantadas em 6 pacientes (Tabela 1), sendo $33,3 \%$ do sexo masculino e $66,7 \%$ do sexo feminino, cujas idades variaram de 5 a 38 anos, com idade média de 21 anos. Tais pacientes foram seguidos por período médio de 2,5 anos (Tabela 5). Entre estes, 66,6\% apresentaram evidências de acometimento valvar pela doença reumática. O grupo de pacientes analisados não apresentou mortalidade hospitalar. Foi observado, ao final de 5 anos, um índice de sobrevida de $86,0 \%$ (Gráfico 1). Neste mesmo período, uma taxa semelhante $(86,0 \%)$ de pacientes encontrava-se livre de complicações (Gráfico 2). Durante o seguimento, ocorreu um episódio de endocardite infecciosa, sendo esta responsável por $100 \%$ da mortalidade tardia (Tabela 4). Foram detectados 6,7 eventos por 100 pacientes-ano referentes à ocorrência de fenômeno de trombose e tromboembolismo (Tabela 5). Neste grupo, não foram realizadas reoperaçőes.

\section{Prótese biológica em posição mitral}

Em relaçāo à prótese biológica de pericárdio bovino IMC-Biomédica, 526 foram implantadas em posição mitral, sendo $34,8 \%$ dos pacientes do sexo masculino e $65,2 \%$ do sexo feminino, com as idades variando de 5 a 72 anos e idade média de 38,7 anos. Em $82,0 \%$ dos casos analisados, a doença reumática pode ser responsabilizada pela disfunçāo valvar (Tabela 1). A mortalidade hospitalar incidiu em $9,5 \%$ dos pacientes, sendo que a insuficiência ventricular esquerda respondeu por $42,0 \%$ do total (Tabela 3 ); $98,6 \%$ dos pacientes foram acompanhados a longo prazo, por período de 1,484 anos-pacientes. Ao final de 9 anos, as curvas de sobrevida foram de $66,0 \%$ e $64,0 \%$ para adultos e jovens, respectivamente, considerando jovens os pacientes com menos de 21 anos na época de internaçāo. A mortalidade tardia se deveu, mais freqüentemente, a morte subita $(21,7 \%)$, seguida por outras causas não especificadas 
BRAILE, D. M.; ARDITO, R. V.; ZAIANTCHICK, M.; SANTOS, J. L. V.; CAMPOS, N. L. K. L.; JACOB, J. L. B.; SOUZA, D. R. S.; RADE, W.; MARTINS, J. I.; LORGA, A. M. - Estudo comparativo entre válvulas biológicas e válvulas mecâcnicas nas posiçōes mitral ou aórtica até 14 anos. Rev. Bras. Cir. Cardiovasc., 3(3): 141-158, 1988.

$(14,5 \%)$, e endocardite infecciosa $(13,0 \%$ ) (Tabela 4$)$. Concluído o período de acompanhamento, $63,0 \%$ dos pacientes achavam-se livres de complicações, como: morte relacionada a prótese, reoperações, tromboses, endocardite, calcificações, roturas, ou vazamento paravalvular (Gráfico 2). Os fenômenos de trombose e tromboembolismo foram detectados com uma freqüência de 1,0 evento por 100 pacientes-ano, enquanto calcificaçōes ou roturas, com uma freqüência de 1,8 eventos por 100 pacientes-ano (Tabela 5).

\section{Próteses mecânicas em posição aórtica}

Na posição aórtica, foram empregadas $336(58,9 \%)$ próteses mecânicas e $234(41,1 \%)$ próteses biológicas (Tabela 1). Em ambos os grupos, a doença reumática foi a mais freqüentemente responsável pela disfunção valvar, com taxas de $71,4 \%, 83,7 \%, 54,9 \%$ e $91,9 \%$ para as próteses PBMIC, B-S, H-K, L-K, respectivamente (Tabela 2).

As próteses Björk-Shiley foram utilizadas em 92 pacientes (Tabela 1), com idades variando de 10 a 71 anos e média de 38,8 anos, sendo $76,1 \%$ dos pacientes do sexo masculino. A mortalidade hospitalar assinalada foi de $5,4 \%$, com o acidente vascular cerebral respondendo por $40.0 \%$ do total e a insuficiência ventricular esquerda, a septicemia e a insuficiência respiratória contribuindo com $20,0 \%$ cada, totalizando os $60,0 \%$ restantes (Tabela 3); $96,5 \%$ dos pacientes foram acompanhados por período médio de 7,1 anos, resultando em 616 pacientes-ano (Tabela 5). De acordo com a curva de sobrevida extraída ao final de 12 anos, $63,0 \%$ dos pacientes achavam-se ainda vivos e $73,7 \%$ achavam-se livres de complicações (Gráficos 3 e 4). A morte súbita foi responsável por $19,3 \%$ da mortalidade tardia, neste grupo de pacientes, seguindo-se a insuficiência cardiaca $(12,9 \%)$ e as arritmias $(9,7 \%)$ (Tabela 4$)$. Em 17,4\% dos casos, houve necessidade de reoperaçōes. Os fenômenos de trombose e tromboembolismo incidiram com uma freqüência de 3,0 eventos por 100 pacientes-ano (Tabela 5).

Em 112 pacientes, foram empregadas próteses do tipo Lillehei-Kaster em posição aórtica (Tabela 1), com idades entre 14 e 61 anos, e idade média de 37,5 anos, sendo $71,1 \%$ dos pacientes do sexo masculino e $28,9 \%$ dos sexo feminino. A mortalidade hospitalar encontrada foi de $5,4 \%$, com a insuficiência ventricular esquerda contribuindo em sua maior parte $(66,6 \%)$ (Tabela 3$)$. Em $98,0 \%$ dos pacientes, foi realizado um seguimento médio de 7,5 anos (Tabela 5). Ao final de 14 anos, $63,0 \%$ dos indivíduos operados achavam-se vivos, enquanto $71,0 \%$ estavam livres de complicaçōes (Gráficos 3 e 4). A morte súbita foi a causa mais freqüente de mortalidade tardia $(29,3 \%)$, outras causas, como a trombose da prótese $(19,3 \%)$ e o acidente vascular cerebral $(16,3 \%)$, também foram detectados (Tabela 4). Neste grupo, tromboses e tromboembolismo ocorreram com indices de 2,3 eventos por 100 pacientes-ano (Tabela 5). Nāo foram necessárias reoperaçōes durante o período analisado.

Os pacientes com implante de prótese Hall-Kaster em posição aórtica totalizaram 133 pacientes (Tabela 1), com idades de 11 a 71 anos e idade média de 36,0 anos, sendo 75,2 do sexo masculino e $33,0 \%$ do sexo feminino. Nestes pacientes, a mortalidade hospitalar foi de $5,3 \%$, registrada como sua causa mais comum a insuficiência ventricular esquerda $(42,9 \%$ ) (Tabela 3$)$. Todos os pacientes deste grupo foram acompanhados por periódo de 1 a 7 anos, com média de seguimento de 4,1 anos.(Tabela 5). A morte súbita foi responsabilizada pela mortalidade tardia de $36,4 \%$ dos casos, a trombose da prótese em $27,4 \%$ e a endocardite em $13,7 \%$ (Tabela 5). Após um período de seguimento de 7 anos, $70,0 \%$ dos pacientes estavam vivos e $75,0 \%$ estavam livres de complicaçōes (Gráficos 3 e 4); $75,0 \%$ dos pacientes necessitaram de reintervenções cirúrgicas. Durante o período de acompanhamento, as tromboses e o tromboembolismo ocorreram com freqüências iguais a 2,5 eventos por 100 pacientes-ano, e as calcificaçōes e roturas com taxas de 0,38 eventos por 100 pacientes-ano (Tabela 5).

\section{Prótese biológica em posição aórtica}

A prótese biológica IMC-Biomédia foi implantada na posição aórtica em 192 pacientes (Tabela 1), sendo $72,2 \%$ dos sexo masculino, em idades variando de 9 a 71 anos, com média de 47,4 anos. A taxa de mortalidade hospitalar foi de $2,6 \%$, com a insuficiência renal aguda contribuindo para $40,0 \%$ dos óbitos, e o tamponamento cardíaco, a insuficiência ventricular esquerda e a hemorragia, para os $60,0 \%$ restantes, com porcentagens iguais a $20,0 \%$ cada (Tabela 3 ).

A taxa de seguimento foi de $98,5 \%$, com tempo médio igual a 1,9 anos (Tabela 5). A endocardite infecciosa contribuiu com $18,1 \%$ para a mortalidade tardia, sendo sua causa mais comum (Tabela 4). A sobrevida dos pacientes foi de $80,0 \%$ em 7 anos, enquanto $88,0 \%$ dos casos analisados achavam-se livres de complicaçōes após o referido periodo (Gráficos 3 e 4). Em 3,7\% dos casos, foram necessárias reoperações. As taxas de trombose/tromboembolismo e calcificaçōes/roturas foram de 0,3 eventos por 100 pacientes-ano e 0,54 eventos por 100 pacientes-ano, respectivamente (Tabela 5). Os resultados encontrados referentes às complicaçōes tardia, fatais e nāo fatais, acham-se expressos nas Tabelas 6 e 7 , respectivamente.

\section{DISCUSSĀO}

No Brasil, um problema com o qual o cirurgião cardiovascular freqüentemente se depara sāo as valvopa- 
BRAILE, D. M.; ARDITO, R. V.; ZAIANTCHICK, M.; SANTOS, J. L. V.; CAMPOS, N. L. K. L.; JACOB, J. L. B.; SOUZA, D. R. S.; RADE, W.; MARTINS, J. I.; LORGA, A. M. - Estudo comparativo entre válvulas biológicas e válvulas mecâcnicas nas posiçōes mitral ou aórtica até 14 anos. Rev. Bras. Cir. Cardiovasc., 3(3): 141-158, 1988.

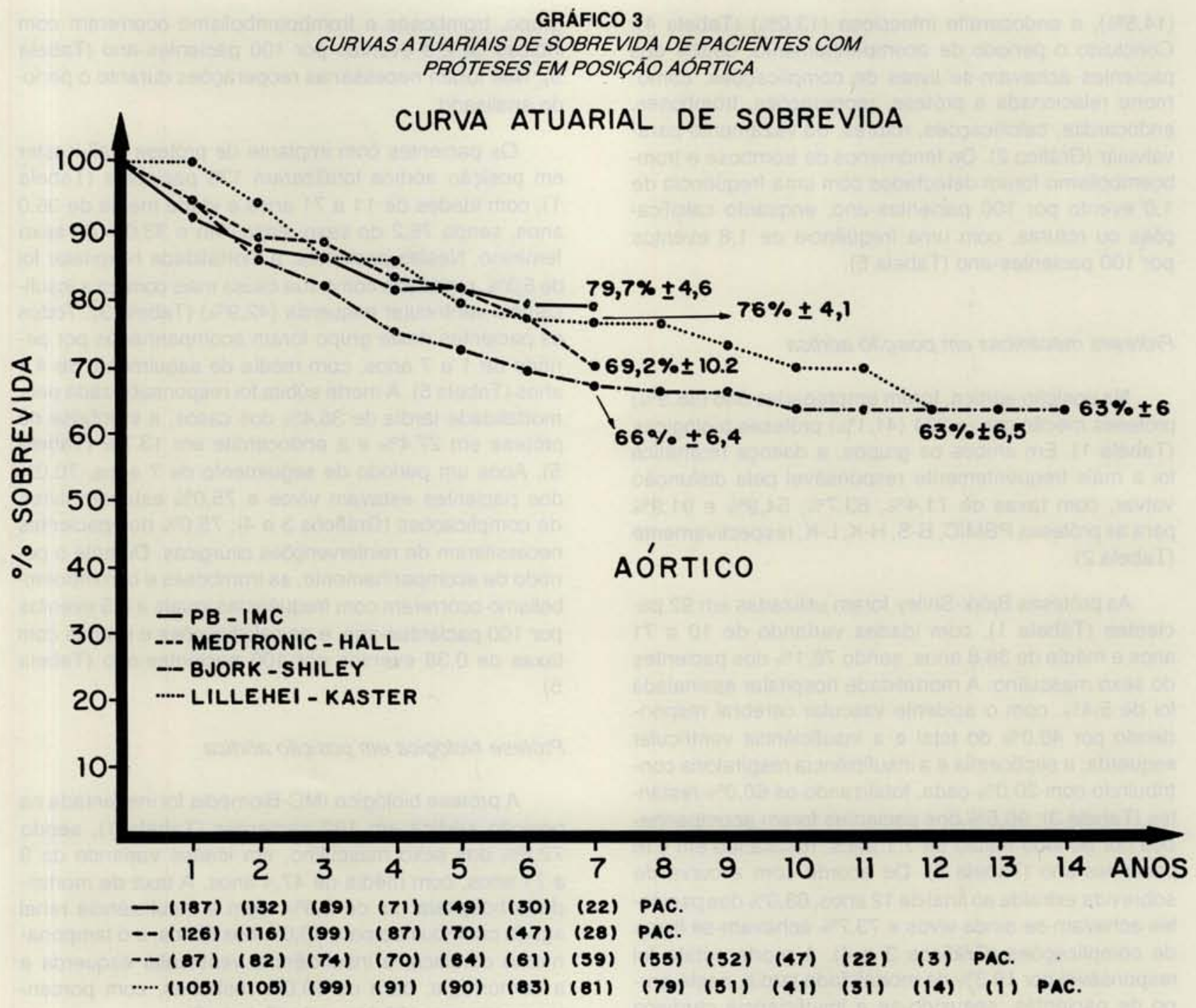

tias decorrentes de diversas etiologias, mas, principalmente, devido à doença reumática. ainda não controlada. especialmente na população mais carente. De 4723 cirurgias nas quais se empregou a circulação extracorpórea, 2383 , ou seja, $50,0 \%$ foram realizadas com o intuito de se corrigirem tais valvopatias. Nestas circunstâncıas, recai sobre o cirurgiāo a escolha do tipo de prótese mais adequado ao seu paciente. As próteses metálicas trazem consigo os riscos de fenômenos tromboembólicos, além da proliferação de tecido cicatricial, que acaba por interferir em suas funçōes. Por outro lado, as próteses biológicas sofrem processos de degeneração, de deposição de matriz calcárea, o que, por vezes, obriga à sua substituiçăo.

Os resultados de trocas valvares podem ser medidos, a longo prazo, pela sobrevida dos pacientes, regressāo da sintomatologia, bem como pela ausência de complicações no periodo de pós-operatório, em especial aquelas relacionadas ao mau funcionamento da prótese, ao tromboembolismo e à terapia anticoagulante. Tais resultados podem, no entanto, ser influenciados pela seleção dos pacientes submetidos a cirurgia, tipo de prótese empregado e cuidados pós-operatórios dispensados.

Analisaremos, inicialmente, o comportamento dos pacientes submetidos ao implante dos diferentes tipos de próteses em posição mitral. As válvulas a serem empregadas nesta topografia são as próteses mecânicas, ou as próteses biológicas.

Os pacientes submetidos ao implante de próteses do tipo Björk-Shiley apresentaram a insuficiência ventricular esquerda como o principal determinante da mortalidade tardia, talvez porque a indicação cirúrgica foi tardia neste grupo de pacientes, bem como devido ao fato de, em alguns casos,os pacientes já serem portadores de valvas com disfunçāo (Tabela 4). A curva de sobrevida extraída do seguimento de tais pacientes revelou que, 
BRAILE, D. M.; ARDITO, R. V.; ZAIANTCHICK, M.; SANTOS, J. L. V.; CAMPOS, N. L. K. L.; JACOB, J. L. B.; SOUZA, D. R. S.; RADE, W.; MARTINS, J. I.; LORGA, A. M. - Estudo comparativo entre válvulas biológicas e válvulas mecâcnicas nas posiçōes mitral ou aórtica até 14 anos. Rev. Bras. Cir. Cardiovasc., 3(3): 141-158, 1988.

\section{GRÁFICO 4}

CURVAS ATUARIAIS DE PACIENTES COM PRÓTESES EM POSICYAOO AÓRTICA LIVRES DE COMPLICAÇÕES

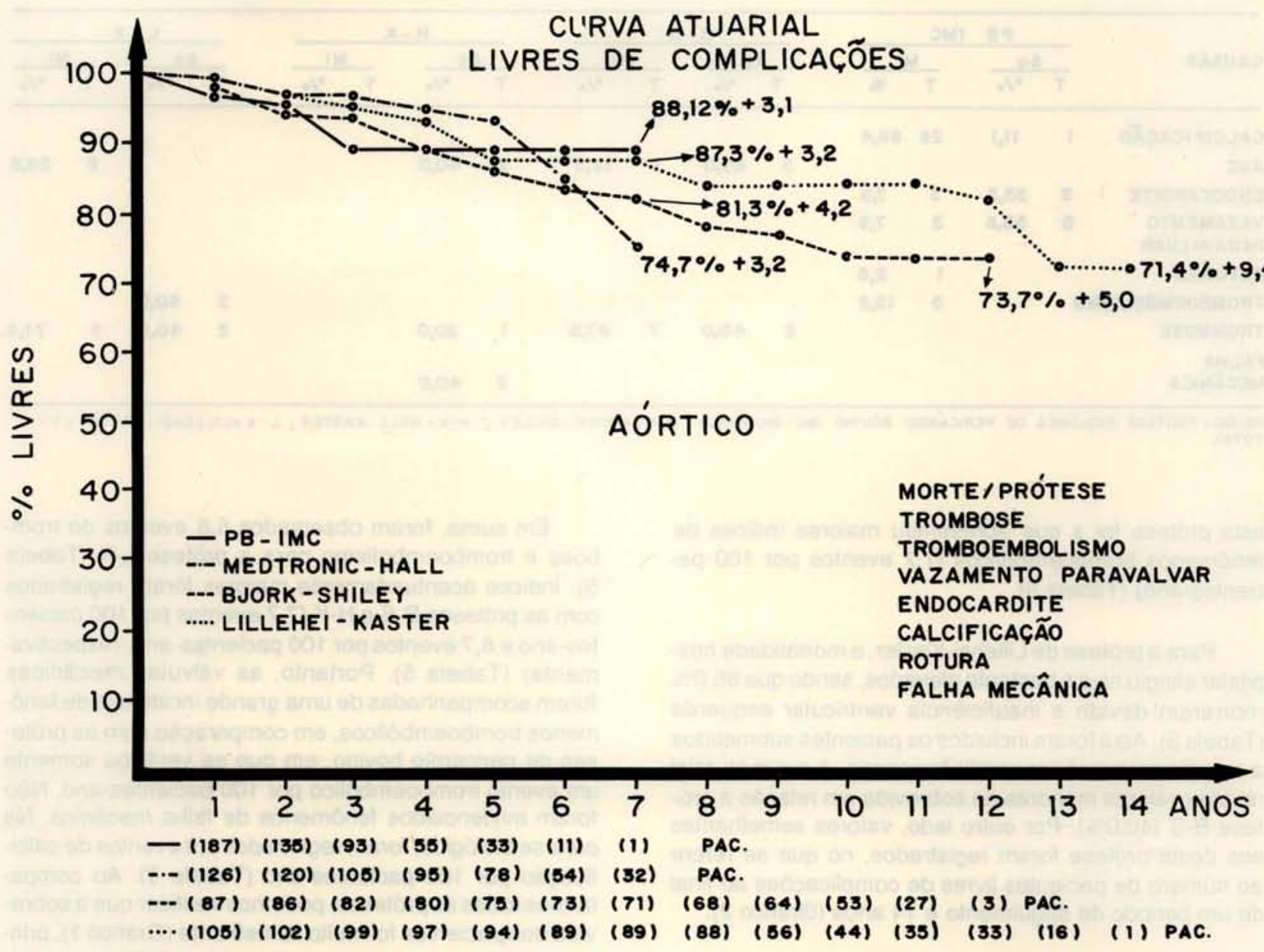

TABELA 6

COMPLICAÇÖES TARDIAS FATAIS EM PACIENTES COM PRÓTESES MECANNICAS OU BIOLOGICAS EM POSIÇÃO AÓRTICA OU MITRAL

\begin{tabular}{|c|c|c|c|c|c|c|c|c|c|c|c|c|c|c|c|c|}
\hline \multirow{3}{*}{ CAUSAS } & \multicolumn{4}{|c|}{ PB } & \multicolumn{4}{|c|}{ B-s } & \multicolumn{4}{|c|}{$M-K$} & \multicolumn{4}{|c|}{$\mathbf{L}-\mathbf{K}$} \\
\hline & \multicolumn{2}{|c|}{ Ao } & \multicolumn{2}{|c|}{$\mathrm{MI}$} & \multicolumn{2}{|c|}{$\Delta$} & \multicolumn{2}{|c|}{$\mathrm{Mi}$} & \multicolumn{2}{|c|}{$\Delta 0$} & \multicolumn{2}{|c|}{ Mi } & \multicolumn{2}{|c|}{ Ao } & \multicolumn{2}{|c|}{ MI } \\
\hline & $\bar{T}$ & $\%$ & $\bar{T}$ & $\%$ & $\bar{T}$ & $\%$ & $\bar{T}$ & $\%$ & $\bar{T}$ & $\%$ & $\bar{T}$ & $\%$ & $\bar{T}$ & $\%$ & $\bar{T}$ & $\%$ \\
\hline TROMBOSE & & & & & 15 & 93,0 & 9 & 75,0 & 6 & 605 & & & 6 & 46,1 & 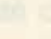 & \\
\hline AVC & tar & trat & ins & (n) & 1 & 6,2 & 1 & 8,3 & 1 & 10,0 & & & 5 & 38,5 & 1 & 7,2 \\
\hline ENDOCARDITE & fis & & & $x^{2}$ & & & 2 & 16,7 & 3 & 30,0 & & nat & 2 & 15,4 & & \\
\hline $\begin{array}{l}\text { TROMBOSE DE } \\
\text { PRÓTESE }\end{array}$ & & & 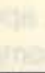 & & & & & & & & & & & & 13 & 92 \\
\hline
\end{tabular}

PB IMC = PRÓTESE BIOLÓGICA DE PERICÁRDIO BOVINA IMC - BIOMÉDICA; B -S = BJORK - SHILEY; H -K = HALL -KASTER ; L-K =LILLEHEI - KASTER; AO = POSICAOO AÓRTICA; Mi = POSICÁ̃O MITRAL; T=TOTAL.

ao final de 14 anos, $55,0 \%$ estavam vivos (Gráfico 1 ). Por outro lado, apenas $44,0 \%$ achavam-se livres de complicaçōes. Nos primeiros anos, observou-se uma redução significativa do número de pacientes livres de compli- caçōes, estabilizando-se, a seguir, e, posteriormente, sofrendo uma nova redução e estabilização ulterior (Gráfico 2). Isto corresponde, principalmente, às tromboses e a pannus que se formam. Quanto a este aspecto, 
BRAILE, D. M.; ARDITO, R. V.; ZAIANTCHICK, M.; SANTOS, J. L. V.; CAMPOS, N. L. K. L.; JACOB, J. L. B.; SOUZA, D. R. S.; RADE, W.; MARTINS, J. I.; LORGA, A. M. - Estudo comparativo entre válvulas biológicas e válvulas mecâcnicas nas posiçōes mitral ou aórtica até 14 anos. Rev. Bras. Cir. Cardiovasc., 3(3): 141-158, 1988.

TABELA 7

COMPLICAÇŌES TARDIAS NĀO-FATAIS EM PACIENTES COM PRÓTESES MECANICAS OU BIOLÓGICAS EM POSIÇÃO AORTICA OU MITRAL

\begin{tabular}{|c|c|c|c|c|c|c|c|c|c|c|c|c|c|c|c|c|}
\hline \multirow{3}{*}{ CAUSAS } & \multicolumn{4}{|c|}{ PB IMC } & \multicolumn{4}{|c|}{$B-S$} & \multicolumn{4}{|c|}{$\mathrm{H}-\mathrm{K}$} & \multicolumn{4}{|c|}{$L-K$} \\
\hline & \multicolumn{2}{|c|}{ Ao } & \multicolumn{2}{|c|}{$\mathrm{Mi}$} & \multicolumn{2}{|c|}{ Ao } & \multicolumn{2}{|c|}{ M1 } & \multicolumn{2}{|c|}{ AO } & \multicolumn{2}{|c|}{$\mathrm{Mi}$} & \multicolumn{2}{|c|}{ Ao } & \multicolumn{2}{|c|}{$\mathrm{Mi}$} \\
\hline & $T$ & $\bullet$ & $T$ & \% & $T$ & $\%$ & $T$ & $\%$ & $T$ & $\%$ & $T$ & $\%$ & $T$ & $\%$ & $T$ & $\%$ \\
\hline CALCIFICAÇ̃̃o & 1 & 11,1 & 26 & 68,4 & & & & & & & & & & & & \\
\hline AVC & & & & & 3 & 60,0 & 1 & 12,5 & 2 & 40,0 & & & & & 2 & 28,6 \\
\hline ENDOCARDITE & 3 & 33,3 & 3 & 7,9 & & & & & & & & & & & & \\
\hline $\begin{array}{l}\text { VAZAMENTO } \\
\text { PARAVALVAR }\end{array}$ & 5 & 55,6 & 3 & 7,9 & & & & & & & & & & & bre & \\
\hline ROTURAS & & & 1 & 2,6 & 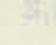 & 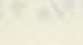 & 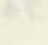 & & & & & & & & & \\
\hline TROMBOEMBOLISMC & & 6 & 5 & 13,2 & & & & & & & & & 3 & 60,0 & & \\
\hline TROMBOSE & & & & & 2 & 40,0 & 7 & 87,5 & 1 & 20,0 & & & 2 & 40,0 & 5 & 71,4 \\
\hline $\begin{array}{l}\text { FALHA } \\
\text { MECẤNICA }\end{array}$ & & & & & & & & & 2 & 40,0 & & & & & 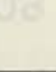 & \\
\hline
\end{tabular}

PB IMC = PRÓTESE BIOLÓGICA DE PERICÁRDIO BOVINO IMC-BIOMÉDICA ; B-S = BJORK - SHILEY; H-K= HALL-KASTER ; L-K =LILLEHEI-KASTER; T = TOTAL.

esta prótese foi a que apresentou maiores índices de fenômenos tromboembólicos $(7,7$ eventos por 100 pacientes-ano) (Tabela 5).

Para a prótese de Lillehei-Kaster, a mortalidade hospitalar atingiu niveis bastante elevados, sendo que $86,0 \%$ morreram devido a insuficiência ventricular esquerda (Tabela 3). Aqui foram incluídos os pacientes submetidos a cirurgia em precárias condiçōes gerais. A curva atuarial revelou valores menores de sobrevida em relação à prótese B-S $(40,0 \%)$. Por outro lado, valores semelhantes aos desta prótese foram registrados, no que se refere ao número de pacientes livres de complicaçōes ao final de um período de seguimento e 14 anos (Gráfico 2).

As próteses Hall-Kaster foram utilizadas somente nos últimos anos. Ao final do período de seguimento, $86,0 \%$ dos pacientes achavam-se vivos e livres de complicaçōes (Gráficos 1 e 2)

Quanto às biopróteses IMC-Biomédica, valores mais elevados do que os mencionados na literatura consultada (IONESCU et alii ${ }^{19,20}$, OTT et alii ${ }^{30,31}$, REUL Jr. et alii ${ }^{34}$, NASHEF et alii ${ }^{27}$ ), foram registrados em relação às taxas de mortalidade hospitalar. Entretanto, nos últimos 5 anos, tal índice reduziu-se de $9,5 \%$ para $3,5 \%$, em parte devido ao aperfeiçoamento das técnicas utilizadas em cirurgias valvares, bem como devido ao surgimento de novas técnicas de cardioplegia e de proteção miocárdica. A sobrevida deste grupo foi maior para os pacientes adultos $(66,0 \%)$ do que para os jovens $(64,0 \%)$, ao final de 9 anos de acompanhamento. Consideramos jovens os pacientes com idade inferior a 21 anos; $63,0 \%$ dos pacientes achavam-se livres de complicaçōes, morte pela prótese, reoperaçāo, tromboembolismo, endocardite, calcificação, roturas e vazamento paravalvular (Gráfico 2).
Em suma, foram observados 5,6 eventos de trombose e tromboembolismo para a prótese L-K (Tabela 5). Índices acentuadamente maiores foram registrados com as próteses B-S e H-K (7,7 eventos por 100 pacientes-ano e 6,7 eventos por 100 pacientes-ano, respectivamente) (Tabela 5). Portanto, as válvulas mecânicas foram acompanhadas de uma grande incidência de fenômenos tromboembólicos, em comparaçāo com as próteses de pericárdio bovino, em que se verificou somente um evento tromboembólico por 100 pacientes-ano. Não foram evidenciados fenômenos de falha mecânica. $\mathrm{Na}$ prótese biológica, foram registrados 1,8 eventos de calcificação por 100 pacientes-ano (Tabela 5). Ao compararmos todas as próteses, podemos verificar que a sobrevida dos pacientes foi muito semelhante (Gráfico 1), principalmente porque os pacientes vêm a falecer não em decorrênia da prótese, mas sim pela doença que os acompanha. Além disso, as curvas de pacientes livres de complicaçōes são semelhantes para os diferentes tipos de próteses empregadas, mostando que o número de complicações das diferentes válvulas é bastante parecido e que a prótese biológica se encontra em posição satisfatória (Gráfico 2). Devemos, ainda, considerar que o emprego de biopróteses dispensa o uso de anticoagulantes, o que, a nosso ver, simplifica o tratamento.

Se compararmos as próteses por nós analisadas com a prótese de Starr-Edwards, verificamos que, após 9 anos de seguimento, apenas $32,0 \%$ destes pacientes achavam-se livres de complicaçōes ', enquanto tal valor elevou-se para 50,0 a 60,0 com o emprego das próteses de disco ou PBIMC (Gráfico 2).

Para a posição aórtica, as próteses do tipo BjörkShiley registraram taxas de mortalidade hospitalar de $5,4 \%$ (Tabela 3 ). Após um período de observação de 12 anos, $63,0 \%$ dos pacientes estavam vivos e $73,7 \%$ encontravam-se livres de complicaçōes (Gráficos 3 e 
BRAILE, D. M.; ARDITO, R. V.; ZAIANTCHICK, M.; SANTOS, J. L. V.; CAMPOS, N. L. K. L.; JACOB, J. L. B.; SOUZA, D. R. S.; RADE, W.; MARTINS, J. I.; LORGA, A. M. - Estudo comparativo entre válvulas biológicas e válvulas mecâcnicas nas posiçōes mitral ou aórtica até 14 anos. Rev. Bras. Cir. Cardiovasc., 3(3): 141-158, 1988.

4). Taxas semelhantes de mortalidade hospitalar foram registradas para a prótese de L-K, sendo que, para este tipo de prótese, $63,0 \%$ dos pacientes estavam vivos e $71,0 \%$ năo apresentaram complicaçōes, ao final de 7 anos (Gráficos 3 e 4).

Quando se utilizou a bioprótese IMC-Biomédica, índices de mortalidade hospitalar muito menores foram registrados, em comparação com as próteses mecânicas. Isto nos permitiu inferir que a PBIMC, pelo menos a curto prazo, é a que mais se aproxima da prótese ideal, por não alterar, de modo significativo, os padrōes de hemodinâmica, como fazem as próteses mecânicas, já que, com estas, a insuficiência ventricular esquerda contribuiu para a maior parte da mortalidade imediata (Tabela 3).

Para as próteses do tipo Lillehei-Kaster, os fenômenos de trombose e tromboembolismo ocorreram com freqüências iguais a 2,3 eventos por 100 pacientes-ano, o que correspondeu a 3 eventos por 100 pacientes-ano a B-S, 2,5 eventos por 100 pacientes-ano para o $\mathrm{H}-\mathrm{K}$ e 0,3 eventos por 100 pacientes-ano para a PBIMC. Para a última, foram registrados 0,54 eventos por 100 pacientes-ano, no que se refere a fenômenos de calcificação e rotura. Portanto, no âmbito geral, nos parece que a válvula de pericárdio bovino teve um bom desempenho, apesar do tempo de seguimento ter sido menor.

As biopróteses, de acordo com os nossos estudos, mostraram-se superiores também às próteses mecânicas, quando analisadas em conjunto, já que, com aquelas, enquanto $88,0 \%$ dos pacientes achavam-se livres de complicaçōes, com estas tais valores reduziram-se para $72,0 \%$ a $75,0 \%$ (Gráficos 3 e 4 ).

Cabe-nos tecer considerações sobre alguns aspectos, tais como as taxas de mortalidade, reoperações, tromboembolismo e calcificação dos diferentes tipos de próteses, agora analisados em conjunto.

Em relação às reoperações, COSTA et alii *, em ensaios iniciais de bioprótese de pericárdio bovino, destacaram este fator como sendo um contribuinte decisivo para a elevação do índice de mortalidade em qualquer posição de implante, totalizando $36,3 \%$ contra $12,0 \%$ entre aqueles operados pela primeira vez. Índices elevados de mortalidade pelo mesmo motivo também foram registrados por outros autores ${ }^{18,30,31}$. Em nosso estudo, pudemos observar índices de mortalidade tardia mais elevados $(42,1 \%)$, naquele grupo de pacientes em que, mais freqüentemente, as reoperações se fizeram necessárias $(52,2 \%$ de reintervençōes cirúrgicas em pacientes com prótese B-S em posição mitral). Neste caso, os efeitos nocivos das reoperações poderiam, pelo menos parcialmente, estar influindo nas taxas de mortalidade observadas, principalmente, após o emprego de próteses mecânicas; tais pacientes são reoperados, geral-

- COSTA et alii. Comunicaçăo pessoal mente, em más condições gerais resultantes de disfunções valvulares súbitas, como, por exemplo, o entrave do oclusor com conseqüente edema agudo dos pulmōes.

Quanto á mortalidade imediata ou hospitalar, OLESEN et alii ${ }^{29}$ relataram, em estudo envolvendo troca mitral com a prótese de L-K um índice notavelmente maior $(13,0 \%)$, quando comparado com pacientes submetidos a troca valvar aórtica (OLESEN et alii ${ }^{28}$ ). Nossos dados concordam com estes apresentados $(21,1 \%$ contra $5,4 \%$ ) e nos permitem inferir que alterações hemodinâmicas significativas ocorrem após o implante deste tipo de prótese em posição mitral, já que a insuficiência ventricular esquerda concorreu para a maior parte de tal mortalidade. Esses resultados são reforçados por aqueles apresentados por MILLER et alii ${ }^{25}$ na avaliação de 3 tipos de próteses valvares cardiacas: B-S, Hancok (H) e Carpentier-Edwards (C-E). Índices igualmente elevados foram registrados por BORKON et alii ${ }^{4}$, diante de um estudo comparativo de próteses mecânicas e biológicas, porém em posição aórtica (12,9\% considerando os 2 tipos de próteses). NASHEF et $a{ }^{i} i^{27}$ não encontraram, por sua vez, diferenças significativas entre os grupos B-S $(76,0 \%)$ e C-E $(6,0 \%)$, quanto à mortalidade hospitalar. Tal fato, segundo OLESEN et alii ${ }^{29}$, foi inesperado e permanece inexplicado.

De acordo com os dados por nós apresentados, exceto com a prótese $\mathrm{H}-\mathrm{K}$, em que não foi observada mortalidade hospitalar em posição mitral, com todos os demais tipos de próteses utilizadas, a mortalidade hospitalar foi menor quando a implantação foi a nível aórtico (Tabela 3). A utilização da prótese PBIMC, tanto em posição aórtica quanto em posição mitral, contribuiu com taxas menores de óbitos intra-hospitalares do que quando foram utilizadas próteses mecânicas. Entretanto, para NASHEF et alii ${ }^{27}$, a mortalidade hospitalar não reflete a escolha da prótese, nem depende da posiçāo de implante, mas está estreitamente ligada ao paciente.

Os pacientes submetidos a trocas valvares cardíacas estão expostos a diversas complicaçōes, as quais podem ser fatais ou não, dependendo, muitas vezes, não só do substituto valvar, mas também do próprio estado do paciente. Desse modo, a mortalidade tardia poderia estar relacionada com várias causas, tais como insuficiência cardiaca, doenças malignas, suicídio, morte súbita ou relacionada à prótese. NASHEF etalii ${ }^{27}$ relataram que causas cardiacas e desconhecidas, provavelmente relacionadas à válvula, e causas não cardíacas destacaram-se entre os determinantes de mortalidade tardia. $\mathrm{Na}$ amostra estudada por eles, a endocardite foi destaque entre as causas de mortalidade tardia, com um índice de $9,8 \%$ para a B-S e $6,4 \%$ para a C-E. Por outro lado, o embolismo foi a causa mais freqüente para a C-E $(9,6 \%)$, comparada à B-S $(7,0 \%)$, com índices de 0,5 a 0,7 por 100 pacientes-ano, para o primeiro fato, e 0,2 a 1,5 por 100 pacientes-ano para o outro. em ambas as posiçōes. 
BRAILE, D. M.; ARDITO, R. V.; ZAIANTCHICK, M.; SANTOS, J. L. V.; CAMPOS, N. L. K. L.; JACOB, J. L. B.; SOUZA, D. R. S.; RADE, W.; MARTINS, J. I.; LORGA, A. M. - Estudo comparativo entre válvulas biológicas e válvulas mecâcnicas nas posiçōes mitral ou aórtica até 14 anos. Rev. Bras. Cir. Cardiovasc., 3(3): 141-158, 1988.

BORKON et alii ${ }^{4}$ registraram altos índices de mortalidade tardia por hemorragia conseqüente ao uso de anticoagulante $(20,0 \%$ para o grupo B-S, diante de $12,0 \%$ de tromboembolismo para o grupo das biopróteses). Um fato bastante conflitante, segundo os autores, é o fato da incidência de tromboembolismo ser maior para as biopróteses do que para a B-S, contrariando outros. Os dados por nós apresentados corroboram os encontrados $9,15,17,22,24,40$, já que, com a prótese L-K, foram observados 5,6 eventos de tromboembolismo por 100 pacientes-ano em posição mitral e 2,3 eventos por 100 pacientes-ano para a posiçāo aórtica, o que correspondeu, respectivamente, a 7,7 eventos por 100 pacientes-ano e 3,0 eventos por 100 pacientes-ano para a B-S e 6,7 eventos por 100 pacientes-ano e 2,5 eventos por 100 pacientes-ano para a H-K. Já com as próteses biológicas, foram observados indices bastante inferiores àqueles registrados com as próteses mecânicas (1 evento por 100 pacientes-ano), mesmo sem a utilização de anticoagulantes.

Para NASHEFet alii ${ }^{27}$ anticoagulaçāo permanente a que estão sujeitos os pacientes com próteses mecânicas não está associada com o aumento do total de pacientes livres de fenômenos tromboembólicos. Deve existir um fator significante, na incidência de embolismos, que não estaria relacionado com a válvula, mas reflete outras variáveis, tais como o ritmo cardiaco e o tamanho do átrio esquerdo.

COHN et alii ${ }^{9}$ e OYER et alii ${ }^{32}$ chegaram a recomendar a anticoagulaçāo a longo prazo para pacientes com dilatação de átrio esquerdo e fibrilação atrial que recebiam uma prótese. No nosso material, nāo temos usado anticoagulantes orais, mesmo na vigẽncia de fibrilação atrial e/ou alargamento do átrio esquerdo e, mesmo assim, os índices de tromboembolismo são muito baixos. Tais resutados poderiam estar relacionados ao uso de antiagregantes plaquetários que evitariam a formação de trombos no período de pós-operatório imediato, decorrentes, fundamentalmente, da adesão das plaquetas às superfícies não recobertas por endotélio, bem como pela boa performance da prótese, do ponto de vista hemodinâmico, que promoveria um clearance permanente do átrio, evitando, assim, a formação de trombos.

Quanto a um outro tipo de complicação relacionada com as próteses cardíacas, cita-se o vazamento paravalvular. Em nossos resultados, tal complicação somente foi obsevada com a utilização de biopróteses, sendo mais freqüente após sua implantação em posição aórtica ( $2,0 \%$ ou 1,35 eventos/100 pacientes-ano), na maioria das vezes relacionadas com a presença de endocardite bacteriana, que representa uma das indicaçōes para uso desta prótese em posição aórtica, sendo responsável por $55,6 \%$ das complicações tardias não fatais relatadas nesta posição e apenas $7,9 \%$ quando foi implantada em posição mitral (Tabela 7).
Com efeito, em se tratando de biopróteses, dentre todas as complicações que afetam este fipo de prótese cardíaca, está a calcificaçāo. OTT et alii ${ }^{30}$, empregando bioprótese lonescu-Shiley em adultos, registraram percentagens de $96,6 \%$ dos pacientes livres de tal complicação, após um período de 5 anos.

Em nosso estudo, pudemos observar índices de calcificação bastante aceitáveis para os indivíduos adultos (maiores que 21 anos), com $80,0 \%$ dos pacientes livres de tal complicação após um periodo de 9 anos de seguimento para a posição mitrale $100,0 \%$ livres da mesma em 7 anos para a posiçāo aórtica (Gráfico 5).

A situação de pacientes jovens diante de uma troca valvar tem sido amplamente discutida. O elevado índice de calcificação $(23,3 \%)$ detectado por WALKER et alii ${ }^{43}$, em pacientes com até 16 anos de idade, com bioprótese Ionescu-Shiley em posição aórtica, em 5 anos de seguimento, levou estes autores a se convencerem de que, embora a calcificação seja extrema em pacientes adolescentes, não deveria ser usado em crianças, independentemente da idade.

De acordo com os nossos estudos, a calcificação esteve presente, tanto na posição aórtica quanto na posição mitral. Entretanto, deve-se considerar que a maior parte desses pacientes pode ser reoperada, e permanece viva e livre de complicações trágicas como a trobose e o tromboembolismo. Poderíamos, ainda, acrescentar, de forma otimista, que um grupo tão grave como o dos jovens com valvopatia apresentou um índice elevado de pacientes livres de complicações, após 9 anos de seguimentos para a posição mitral $(54,0 \%)$, e 7 anos para a posição aórtica $(88,0 \%)$.

\section{CONCLUSŌES}

As próteses mecânicas de disco com fluxo central, apresentam bom desempenho na posiçāo aórtica, mesmo sem o uso obrigatório de anticoagulantes, e mau desempenho na posição mitral, apesar do uso destes, que é obrigatório. Sem a sua utilização, esta válvula é extremamente deletéria. $\mathrm{E}$, mesmo com o seu emprego, temos um elevado número de eventos de tromboembolismo ( 6 a 7 eventos por 100 pacientes-ano).

As próteses biológicas de pericárdio bovino IMCBiomédica apresentam um bom desempenho em posição mitral, sem o uso de anticoagulantes, mesmo em pacientes com fibrilação atrial. Além disso, esta prótese tem um bom desempenho em posição aórtica, considerando um período de 7 anos. Por isso, nós indicamos, de preferência, a prótese biológica para a posição mitral e, para a posiçāo aórtica, é indicada apenas quando existe má função ventricular, anel aórtico estreito, ou calcificado, endocardite bacteriana, mulheres em idade 
BRAILE, D. M.; ARDITO, R. V.; ZAIANTCHICK, M.; SANTOS, J. L. V.; CAMPOS, N. L. K. L.; JACOB, J. L. B.; SOUZA, D. R. S.; RADE, W.; MARTINS, J. I.; LORGA, A. M. - Estudo comparativo entre válvulas biológicas e válvulas mecâcnicas nas posiçôes mitral ou aórtica até 14 anos. Rev. Bras. Cir. Cardiovasc., 3(3): 141-158, 1988.

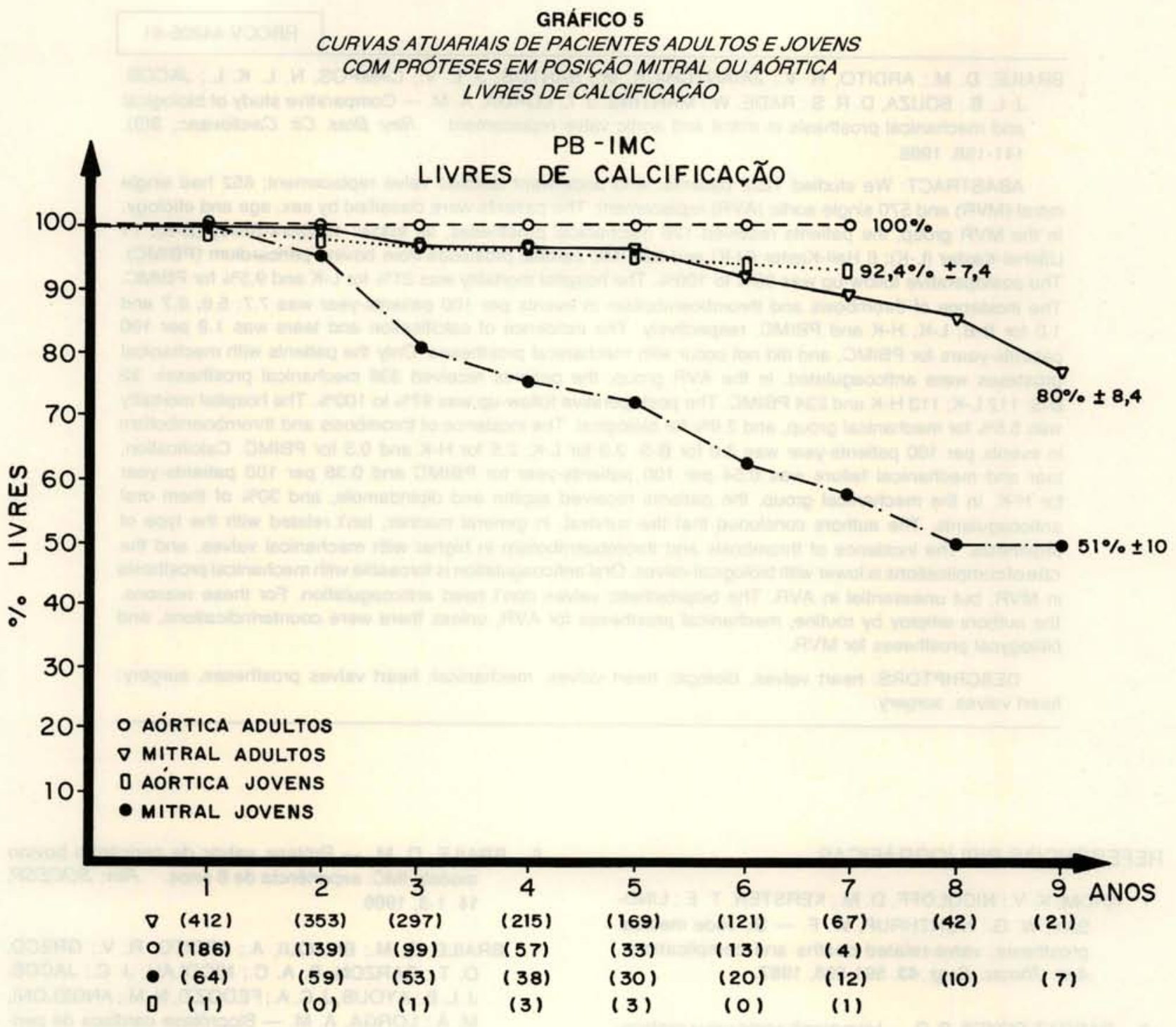

fértil, pacientes idosos, quando existe contra-indicação para a anticoagulação e quando existe válvula biológica em outra posição.

A utilização de próteses biológicas é acompanhada de duas grandes vantagens, em relação às próteses mecânicas: é fácil visibilização pelo ecocardiograma, o que nos possibilita a avaliaçăo de sua performance, quando se fizer necessária, e nāo exige o emprego de anticoagulantes, dispensando, assim, acompanhamento clínico-laboratorial rigoroso, sempre muito difícil, principalmente no nosso meio, além de aliviar os riscos de sangramento que se seguem a tal terapia e que, por vezes, se mostra fatal.

De acordo com os nossos registros, os índices mais elevados de fenômenos de calcificaçāo foram observados com o implante a nível mitral e em pacientes jovens, talvez refletindo o elevado metabolismo do cálcio neste grupo de pacientes. 
BRAILE, D. M.; ARDITO, R. V.; ZAIANTCHICK, M.; SANTOS, J. L. V.; CAMPOS, N. L. K. L.; JACOB, J. L. B.; SOUZA, D. R. S.; RADE, W.; MARTINS, J. I.; LORGA, A. M. - Estudo comparativo entre válvulas biológicas e válvulas mecâcnicas nas posiçōes mitral ou aórtica até 14 anos. Rev. Bras. Cir. Cardiovasc., 3(3): 141-158, 1988.

RBCCV 44205-61

BRAILE, D. M.; ARDITO, R. V.; ZAIANTCHICK, M.; SANTOS, J. L. V.; CAMPOS, N. L. K. L.; JACOB, J. L. B.; SOUZA, D. R. S.; RADE, W.; MARTINS, J. I.; LORGA, A. M. - Comparative study of biological and mechanical prosthesis in mitral and aortic valve replacement. Rev. Bras. Cir. Cardiovasc., 3(3): 141-158, 1988.

ABASTRACT: We studied 1222 patients, who underwent isolated valve replacement; 652 had single mitral (MVR) and 570 single aortic (AVR) replacement. The patients were classified by sex, age and etiology. In the MVR group, the patients received 126 mechanical prostheses, as follow: 49 Björk-Shiley (B-S); 71 Lillehei-Kaster (L-K); 6 Hall-Kaster (H-K) and 526 IMC cardiac prosteses from bovine pericardium (PBIMC). The postoperative follow-up was $95 \%$ to $100 \%$. The hospital mortality was $21 \%$ for L-K and $9,5 \%$ for PBIMC. The incidence of thrombosis and thromboembolism in events per 100 patients-year was $7.7 ; 5.6 ; 6.7$ and 1.0 for B-S; L-K; H-K and PBIMC, respectively. The incidence of calcification and tears was 1.8 per 100 patients-years for PBIMC, and did not occur with mechanical prostheses. Only the patients with mechanical prosteses were anticoagulated. In the AVR group, the patients received 336 mechanical prostheses: 92 B-S; $112 \mathrm{~L}-\mathrm{K} ; 113 \mathrm{H}-\mathrm{K}$ and $234 \mathrm{PBIMC}$. The postoperative follow-up was $97 \%$ to $100 \%$. The hospital mortality was $5.5 \%$ for mechanical group, and $2.6 \%$ for biological. The incidence of thrombosis and thromboembolism in events per 100 patients-year was 3.0 for B-S; 2.3 for L-K; 2.5 for H-K and 0.3 for PBIMC. Calcification, tear and mechanical failure was 0.54 per 100 patients-year for PBIMC and 0.38 per 100 patients-year for $\mathrm{H}-\mathrm{K}$. In the mechanical group, the patients received aspirin and dipiridamole, and $30 \%$ of them oral anticoagulants. The authors concluded that the survival, in general manner, isn't related with the type of prosthesis. The incidence of thrombosis and thromboembolism in higher with mechanical valves, and the rate of complications is lower with biological valves. Oral anticoagulation is forceable with mechanical prosthesis in MVR, but unessential in AVR. The bioprosthetic valves don't need anticoagulation. For these reasons, the authors employ by routine, mechanical prostheses for AVR, unless there were counterindications, and biologycal prostheses for MVR.

DESCRIPTORS: heart valves, biologic; heart valves, mechanical; heart valves prostheses, surgery: heart valves, surgery.

\section{REFERÊNCIAS BIBLIOGRÁFICAS}

1 AROM, K. V.; NICOLOFF, D. M.; KERSTEN, T. E.; LINDSAY, W. G.; NORTHRUP, W. F. - St. Jude medical prosthesis: valve-related deaths and complications. Ann. Thorac. Surg., 43: 591-598, 1987.

2. BARRAT-BOYES, B. G. - Homograft aortic valve replacement in aortic incompetence and stenosis. Thorax, 19:131-150, 1964

3. BEAUDET, R.; POIRIER, N.; BOYLE, D.; NAKHLE, G.; GAUVIN, C. - The Medtronic-Hall cardiac valve: 7,5 years clinical experience. Ann. Thorac. Surg. 42(6): 644-650, 1986.

4. BORKON, A. M.; SOULE, L. M. BAUGHMAN, K. L.; ADUN, H.; BAUNGARTNER, W. A.; GARDNER, T. L.; WATKINS, L.; GOTT, V. L.; REITZ, B. A. - Comparative analysis of mechanical and bioprosthetic valves after aortic valve replacement. J. Thorac. Cardiovasc. Surg., 94(1): 20-33, 1987.

5. BORTOLOTTI, U.; MILANO, A.; THIENE, G.; GUERRA, F.; MAZZUCCO, A.; VALENT, E.; GALLUCCI, V. Long-term durability of the Hancock porcine bioprosthesis following combined mitral and aortic valve replacement and 11 years experience. Ann. Thorac. Surg., 44(2): 139-144, 1987.
6. BRAILE, D. M. - Prótese valvar de pericárdio bovino modelo IMC: experiência de 8 anos. Rev. SOCESP, 14: 1-3, 1986.

7. BRAILE, D. M.; BILAQUI, A.; ARDITO, R. V.; GRECO, O. T.; GARZON, S. A. C.; NICOLAU, J. C.; JACOB, J. L. B.; AYOUB, J. C. A.; FEDOZZI, N. M.; ANGELONI, M. A.; LORGA, A. M. - Bioprótese cardiaca de pericárdio bovino. Arq. Bras. Cardiol. 39: 247-257, 1982.

8. CLELAND, J.; GLADSTONE, D.; HAMILTON, I.; OKANE, H. - A comparison of the St. Jude Medical and the Carpentier-Edwards xenograft valves in the mitral area. Brit. Heart J., 57(1): 100, 1987.

9. COHN, L. H.; ALRED, E. N. COHN, L. A.; AUSTIN, J. C.; SABIK, J.; DISESA, V. J.; SHEMIN, R. J.; COLLINS, J. J. - Early and late risk of mitral valve replacement, J. Thorac. Cardiovasc. Surg., 90(6): 872-882, 1985.

10. COHN, L. H.; KOSTER, J. L.; MEE, R. B. B.; COLLINS Jr., J. J. - Long-term follow-up of the Hancock bioprosthesis heart valve: a six years review. Circulation, 60(Supl. 1): 87-92, 1979.

11. CZER, L. S.; MATLOFF, A.; CHAUX, A.; DE ROBERTIS, M.; STEWART, M. E.; GREY, R. - The St. Jude valve: analysis of thromboembolism, warfarin - related hemorrhage and survival. Am. Heart. J., 114(2): 389-397, 1987. 
BRAILE, D. M.; ARDITO, R. V.; ZAIANTCHICK, M.; SANTOS, J. L. V.; CAMPOS, N. L. K. L.; JACOB, J. L. B.; SOUZA, D. R. S.; RADE, W.; MARTINS, J. I.; LORGA, A. M. - Estudo comparativo entre válvulas biológicas e válvulas mecâcnicas nas posiçōes mitral ou aórtica até 14 anos. Rev. Bras. Cir. Cardiovasc., 3(3): 141-158, 1988.

12. FONTES, R. D.; POMERANTZEFF, P. M. A.; GRINBERG, M.; SNITCOWSKY, R.; VERGINELLI, G.; ZERBINI, E. J.; JATENE, A. D. - Calcificação de bioprótese de dura-máter: estudo em pacientes jovens. Rev. Paul. Med., 103(5): 235-238, 1985.

13. GALLO, I.; NISTAL, F.; BLASQUES, R.; ARBE, E.; ARTINANO, E. - Incidence of primary tissue valve failure in porcine bioprosthetic heart valves. Ann. Thorac. Surg. 45(1): 66-70, 1988.

14. GALLO, I.; NISTAL, F.; REVUELTA, J. M.; GARCI-SATUE, E.; ARTINANO, E.; DURAN, C. G. - Incidence of primary tissue valve failure with the lonescu-Shiley pericardial valve. J. Thorac. Cardiovasc. Surg., $90(2)$ : 278-280, 1985.

15. HAMMOND, G. L.; GEHA. A. S.; KOPT, G. S.; HASHIM S. W. - Biological versus mechanical valves: analysis of 116 valves inserted in 1012 adult patients with a 4818 patient-years follow-up. J. Thorac. Cardiovasc. Surg., 93(2): 182-198, 1987.

16. HARKEN, D. E.; SOROFF, H.S.; TAYLOR, W. J. - Partial and complete prostheses in aortic insuficiency. $J$. Thorac. Cardiovasc. Surg., 40(6): 744-762, 1960.

17. HARTZ, R. S.; FISHER, E. B.; FINKELMEIER, B. - An light-year experience with porcine bioprosthetic cardiac valves. J. Thorac. Cardiovasc. Surg., 91(6): 910-917, 1986.

18. HUSEBYE, D. G.; PLUTH, J. R.; PIEHLER, J. M.; SCHAFF, H. V.; ORSZULAK, T. A.; PUGA, F. J.; DANIELSON, G. K. - Reoperation on prosthetic heart valves. J. Thorac Cardiovasc. Surg., 86(4): 543-552, 1983.

19. IONESCU, M. I.; TANDON, A. P.; CHIDAMBARAM, M.; YAKIREVICH, V. S.; SILVERTON, M. P. - Durability of the pericardial valve. Eur. Heart. J., 85(Supl. D) 101-106, 1984.

20. IONESCU, M. I.; TANDON, A. P.; MARY, D. A. S.; ABID, A. - Heart valve replacement with the lonescu-Shiley pericardial xenograft. J. Thorac. Cardiovasc. Surg., 73(1): 31-42, 1977

21. LAWFORD, P. V.; ROBERTS, R.; DRURY, P. J.; BLACK, M. M. - Valve failure; a pathological and physical study of explanted bioprosthetic valves. Life Support Syst., 4(Supl. 2): 151-153, 1986.

22. MAGILLIGAN Jr, D. J.; LEWS Jr, J. W.; TILLEY, B.; PETERSON, E. - The porcine bioprosthetic valve: twelve years later. J. Thorac. Cardiovas. Surg., 89(4): 499-507, 1985.

23. MAKHLOUF, A. E.; FRIELLI, B.; OBERHANSCI, I.; ROUGE, J. C.; FAIDUTTI, B. - Prosthetic heart valve replacement in children. J. Thorac. Cardiovasc. Surg., 93(1): 80-85, 1987.

24. ARTINELLI, J.; FRAILE, J.; ARTIZ, V.; MORENO, J.; RABAGO, G. - Long-term comparative analysis of the
Björk-Shiley and Hancock valves implanted in 1975 J. Thorac. Cardiovasc. Surg., 90(5): 741-749, 1985.

25. MILLER, H. C.; BLOOMFIELD, P.; KITCHIN, A. H.; WHEATLEY, D. J.; WALBAUM, P. R.; LUTZ, W. Evaluation of three heart valve prostheses. Cardiol. Board Rev., 4(1): 25-43, 1987.

26. NARDUCCI, C.; RUSSO, L.; GIANNELLA, S.; CHIANTERA, A.; ALESSANDRO, L. C. - Identification of dysfunction patterns of cardiac bioprosthesis. Life Support Syst, 4(2): 124-126, 1986.

27. NASHEF, S. A. M.; SETHIA, B.; TURNER, M. A.; DAVIDSON, K. G.; LEWIS, S.; BAIN, W. H. - Bjork-Shiley and Carpentier-Edwards valves. J. Thorac. Cardiovasc. Surg, 93(3): 394-404, 1987.

28. OLESEN, K. H.; RYGG, I. H.; WENNEVOLD, A.; NYBOE, J. - Long-term follow-up in 262 patients after aortic valve replacement with the Lillehei-Kaster prosthesis: overall results and prosthesis related complications. Eur. Heart J.,7(9): 808-816, 1986

29. OLESEN, K. H.; RYGG, I. H.; WENNEVOLD, A.; NYBOE J. - Long-term follow-up in 185 patients after mitral valve replacement with the Lillehei-Kaster prosthesis overall results and prosthesis related complications. Eur. Heart. J., 8(7): 680-688, 1987.

30. OTT, D. A.; COELHO, A. T.; COOLEY, D. A.; REUL Jr, G. J. - lonescu-Shiley pericardial xenograft valve: hemodinamic evaluation and early clinical follow-up of 326 patients. Cardiovasc. Dis.,7(1): 137-149, 1980.

31. OTT, D. A.; COOLEY, D. A.: REUL, Jr., G. J.; DUNCAN. J. M.; FRAZIER, O. H.; LIVESAN, J. J. - IonescuShiley bovine pericardial bioprostheses. Cardiol. Clin., 3(4): 343-369, 1985.

32. OYER, P. E., STINSON, E. B.; RETZ, B. A.; MILLER, D. C.; ROSSITER, S. J.; SHUMWAY, N. E. - Longterm evaluation of the porcine xenograft bioprosthesis. J. Thorac. Cardiovasc. Surg., 78(3): 343-350, 1979.

33. PLUTH, J. R. - The Starr-Edwards mitral valve. In: IONESCU, M. I. \& COHN, L. H. Mitral valve disease. Boston. Butterworth \& Co, 1985. p.217-220.

34. REUL Jr., G. J.; COOLEY, D. A.; DUNCAN, J. M.; FRAZIER, O. H.; HALLMAN, G. L.; LIVESAY, J. J.; OTT, D. A.; WALKER, W. E. - Valve failure with the lonescuShiley bovine pericardial bioprostheses: analysis of 2680 patients. J. Vasc. Surg., 2(1): 192-204, 1985.

35. ROSS, D. N. - Homograft replacement of the aortic valve. Lancet, 2: 487, 1962.

36. SCHOEN, F. J. - Cardiac valve prostheses: pathological and bioengineering consideration. J. Cardiovasc. Surg., 2(1): 65-108, 1987.

37. SCHOEN, F. J.; FERNANDEZ, J.; GONZALES-LAVIN, L.; CEARNAIANU, A. - Causes of failure and patho- 
BRAILE, D. M.; ARDITO, R. V.; ZAIANTCHICK, M.; SANTOS, J. L. V.; CAMPOS, N. L. K. L.; JACOB, J. L. B.; SOUZA, D. R S.; RADE, W.: MARTINS, J. I.; LORGA, A. M. - Estudo comparativo entre válvulas biológicas e válvulas mecâcnicas nas posiçōes mitral ou aórtica até 14 anos. Rev. Bras. Cir. Cardiovasc., 3(3): 141-158, 1988.

logic findings in surgically removed lonescu-Shiley standard bovine pericardial heart valve bioprostheses: emphasis on progressive structural deterioration. Circulation, 76(3): 618-627, 1987.

SCHOEN, F. J.; KUJOWICH, J. L.; WEBB, C. L.; LEVY, R. J. - Chemically determined mineral content of explantd porcine aortic valve bioprostheses: correlation with radiographic assessment of calcification and clinical data. Circulation, 76(5): 1061-1066, 1987.

39. SCHOEN, F. J.; TSAO, J. W.: LEVY, R. J. - Calcification of bovine pericardium used in cardiac valve bioprostheses. Ann. J. Pathol., 123(1): 134-145, 1986.

40. SETHIA, B.; TURNER, M. A.; LEWIS, S.; RODGER, R. A.; BAIN, W. H.; KOUCHOWKOS, N. T. - Fourteen years experiẻnce with the Björk-Shiley tilting disc prosthesis. J. Thorac. Cardiovasc. Surg., 91(3): 350-361, 1986.

41. STARNES, V. A. \& MILLER, D. C. - Selecting a prosthetic valve. In: FORTUIN, N. J. Current therapy in cardiovascular disease. Philadelpha, B. C. Decker Inc., 1987. p. 77-79.

42. STARR, A. \& EDWARDS, M. L. - Mitral replacement: clinical experience with a ball-valve prosthesis. Ann. Surg., 154(8): 726-731, 1961.

43. WALKER, W. E.: DUNCAN, J. M.; FRAZIER Jr., O. H.: LIVESAY, J. J.; OTT, D. A.; REUL, G. J.; COOLEY, D. A. - Early experience with the lonescu-Shiley pericardial xenograft valve. J. Thorac. Cardiovasc. Surg., 86(4): 570-575, 1983

AGRADECIMENTO: Agradecemos à equipe técnica da IMC-Biomédica pelos serviços prestados, no que se refere à elaboraçāo deste trabalho.

\section{Discussão}

\section{DR. RANDAS BATISTA \\ Curitiba, $P R$}

Gostaria de perguntar ao Dr. Braile, o que eu li, em seu resumo, sobre a mortalidade; notei que, nas próteses biológicas, era de $60 \%$ a $70 \%$ menor que nas próteses metálicas; sou um adepto das próteses biológicas, mas acho que, com a metálica, a cirurgia é mais simples de ser executada. Então, não entendi a razão dessa disparidade significante. Em segundo lugar, gostaria de agradecer à Comissão Organizadora deste Congresso a oportunidade que me deu de compartilhar com os senhores.

\section{DR. JANUÁRIO DE SOUZA São Paulo, SP}

Em primeiro lugar, quero cumprimentar o Dr. Braile. Já sabemos, de há muito, do seu interesse pela substituição valvar, e que é um dos grandes batalhadores em nosso meio. Desde que o primeiro substituto valvar foi usado, estamos à procura de um substituto que seja ideal. Os dois maiores problemas, como já ficou enfatizado, são a falha primária da bioprótese e o tromboembolismo, ou trombose, relacionada à prótese mecânica. O interesse é reenfatizar, como foi feito pelo Dr. Braile, que as complicaçōes trombóticas das próteses mecânicas geralmente são muito mais graves e causam situações de maior emergência do que as complicaçôes de uma prótese biológica. No presente trabalho, acho que ficou claro que a reincidência de tromboembolismo, mesmo com o uso de anticoagulantes em próteses mecãnicas em posição mitral, inviabiliza o uso dessas próteses, pelo menos em nosso meio, onde é difícil o controle, na posição aórtica. $\mathrm{O}$ trabalho também mostra que, embora houvesse um cuidado com o uso de anticoagulante, em $30 \%$ dos casos de uso de anticoagulante houve incidência significativa de tromboembolismo; nós sabemos que é dificil manter pacientes com anticoagulante, pelo problema do controle laboratorial, em locais distantes das grandes cidades e o uso de dipiridamol, também a longo prazo, tem dificuldade, pelo preço elevado da droga. Tendo em vista esses problemas, como já foi apresentado no trabalho de número 2 da nossa equipe, nós temos utilizado apenas próteses biológicas, reservando as próteses mecânicas para situaçōes de exceção. Nós sabemos que a utilização de uma bioprótes subentende a necessidade da retroca em período não determinado, mas, como já foi demonstrado, em geral após o sétimo ano; sabemos que a evoluçāo do controle desses pacientes deve ser rigoroso, para que sejam operados antes que tenham uma situação de emergência. Exatamente a grande vantagem da biprótese é poder-se operar um doente em situaçāo hemodinâmica boa, com risco cirúrgico igual ao da primeira troca. A minha primeira pergunta é sobre o que o Dr. Randas já fez e que me causou surpresa, a diferença tão gritante entre o resultado imediato da bioprótese e da prótese mecânica na posição mitral, quanto á sobrevida; outra pergunta é se o autor tem algum estudo de problema grave de sangramento com uso de anticoagulante, nesses pacientes. Mais uma vez, quero cumprimentar o autor, pela excelente apresentação, pelos resultados e pelo grande número de pacientes. Muito obrigado.

\section{DR. TOMÁS A. SALERNO Toronto, Canadá}

Os meus comentários serăo muito breves; o meu amigo Dr. Braile apresentou um trabalho excelente, eu sei e a audiência sabe que o seu conhecimento e sua 
BRAILE, D. M.; ARDITO, R. V.; ZAIANTCHICK, M.; SANTOS, J. L. V.; CAMPOS, N. L. K. L.; JACOB, J. L. B.; SOUZA, D. R. S.; RADE, W.; MARTINS, J. I.; LORGA, A. M. - Estudo comparativo entre válvulas biológicas e válvulas mecâcnicas nas posiçōes mitral ou aórtica até 14 anos. Rev. Bras. Cir. Cardiovasc., 3(3): 141-158, 1988.

liderança, nessa área de cirurgia valvular, chega ao Exterior; eu conheço bem o seu trabalho, tenho concordância com tudo o que foi dito. Uma palavra sobre o cuidado que vocês devem tomar em ter uma idéia aberta sobre os tipos de válvulas que estamos usando. No momento, nos Estados Unidos e no Canadá, estamos vivendo uma fase muito difícil, com relação ao uso de válvulas, especialmente devido ao problema médico-legal. Como vocês sabem, a válvula de Björk-Shiley foi descontinuada, devido a falha mecânica e, no momento, a válvula de Yonescu-Shiley, que é feita de pericárdio, também foi descontinuada. Então, os cirurgiōes estão tendo tendência para válvula mecânica. Infelizmente, tenho que discordar do meu amigo Dr. Braile, com relaçāo ao uso de anticoagulantes em válvulas metálicas; pelo menos no nosso país, não é aceito colocar uma válvula metálica em qualquer posição, se o paciente segue em ritmo normal, ou fibrilante, e não dar anticoagulante. Com relação à prótese de pericárdio, que era a minha favorita, não há necessidade do uso de anticoagulante, como falarei para vocês, em minha apresentação de amanhã; outra coisa é que está havendo uma mudança na prática de válvulas, no nosso país, em que vocês, muito em breve, não farão mais operação para valva estenótica, seja valva mitral estenótica, ou valva aórtica estenótica, porque os nossos cardiologistas estão tomando conta deste aspecto para nós, usando a valvoplastia. Ao terminar meus comentários, desejo elogiar o meu amigo Dr. Braile e lhe dar parabéns pelo excelente trabalho. Muito obrigado.

\section{DR. LUIZ CARLOS BENTO DE SOUZA} São Paulo, SP

Quero comprimentar o grupo de São José do Rio Preto e a excelente apresentação do Dr. Braile, sobre esse assunto tão importante. Queria fazer um comentário sobre o que o Dr. Braile nos expôs sobre os resultados da válvula de Starr-Edwards, com os quais eu, pessoalmente, não concordo. Acredito que a série apresentada por ele, como comparação com todos os outros tipos de válvulas, da experiência da Stanford, não sei se são perfeitamente superponiveis à experiência do Dr. Starr, da Mayo Clinic, e também não é igual àquela que foi estudada no nosso Serviço; em 1978, a Dra. Zilda Meneguello fez um levantamento dos doentes que tinham 14 anos de válvula de Starr, colocada no Serviço, e o resultado, seguramente, não é superponivel a este que foi aqui mostrado. A sensação, para quem assistiu à apresentação do trabalho, é de que as válvulas de disco basculante e as biológicas produzem um resultado $\mathrm{X}$, e as válvulas de Starr-Edwards, um resultado totalmente inferior. Eu não concordo com este posicionamento; acho, pelo que li das experiências do Dr. Starr, da experiência da Mayo Clinic e da experiência própria do Instituto Dante pazzanese de Cardiologia, que os resultados tardios da válvula de Starr-Edwards, principalmente aquelas utilizadas em posição aórtica, são perfeitamente superponíveis aos resultados das válvulas de Hall-Kaster, Björk-Shiley em posição aórtica, de tal forma que considero, hoje em dia, existirem válvulas de desenho mecânico mais atuais e mais apropriadas para uso em posição atrioventricular e, pessoalmente, a minha preferência, para uma prótese em posição atrioventricular, não recai sobre a prótese de Starr-Edwards, que considero um desenho mecânico algo desatualizado para essa posição; entretanto, para a posição aórtica, considero ainda a prótese Starr-Edwards uma prótese perfeitamente competitiva e que produz resultados a longo prazo superponiveis, em número equalidade, a esses apresentados pelas outras próteses. Muito obrigado.

\section{DR. DOMINGO BRAILE (Encerrando)}

Agradeço a todos os comentários que enriqueceram, de maneira muito especial, o nosso trabalho. Quando montei esta apresentação, omiti o problema da mortalidade, porque já estava no resumo; realmente, as séries não são comparáveis; insisti, várias vezes, nisto, porque aquelas válvulas foram operações feitas há 14 anos e a mortalidade imediata era muito maior, mesmo porque estávamos operando doente em grupo de risco muito mais alto, grau IV, etc. Para que se tenha uma idéia, mesmo na prótese de pericárdio bovino, por exemplo, a nossa mortalidade global é $9,5 \%$; no entanto, a mortalidade, nos últimos 5 anos, é de $4 \%$ e, nos últimos 2 anos, é de $2 \%$; é lógico que nós melhoramos isto; temos que admitir publicamente e fica mais do que claro que existe uma curva de aprendizado e que o doente paga por isso, infelizmente. Quanto à calcificaçāo de que o $\mathrm{Dr}$. Randas falou, realmente este é um assunto difícil de ser interpretado; nós já tínhamos este tipo de experiência; se você pega uma tira de pericárdio e coloca dentro do átrio do carneiro, por exemplo, nunca se calcifica, o que é muito interessante, ele fica solto, nāo tem nenhum stress mecânico; a calcificação tem uma relação direta com o stress mecânico; por isto é que, todos nós sabemos, se uma lascínia não se abre, ela vai se calcificar; se o doente tem uma insuficiência aórtica não cirúrgica duas cruzes e você troca a valva mitral, ele tem muito mais chance de ter a válvula mitral calcificada, porque vai ser submetida a um regime de maior pressão, por estar exposta ao jato de insuficiência aórtica, vai calcificar mais depressa. Então, realmente, calcificação tem um fator tecidual, fator humoral, cálcio circulante que funciona, porque o indivíduo que tem insuficiência renal crônica também calcifica rapidamente, a criança calcifica rapidamente; talvez exista um mecanismo, que o Dr. Ênio Buffolo procurou demonstrar aqui, de antígeno-anticorpo, e existe, não há dúvida, stress mecânico. Quanto aos comentários a respeito da prótese em posição aórtica, na realidade nós colocamos a prótese aórtica no melhor paciente, aquele que não tem calcificação, cujo ventrículo é bom, que não tem endocardite presente; 
BRAILE, D. M.; ARDITO, R. V.; ZAIANTCHICK, M.; SANTOS, J. L. V.; CAMPOS, N. L. K. L.; JACOB, J. L. B.; SOUZA, D. R. S.; RADE, W.; MARTINS, J. I.; LORGA, A. M. - Estudo comparativo entre válvulas biológicas e válvulas mecâcnicas nas posiçōes mitral ou aórtica até 14 anos. Rev. Bras. Cir. Cardiovasc., 3(3): 141-158, 1988.

então, nosso resultado, para a prótese aórtica metálica, é muito bom e, por isso, a gente consegue anticoagular somente $30 \%$ deles, aqueles doentes que achamos que têm mais risco, menor débito cardíaco, que tenham algum problema no momento da cirurgia. Uma coisa é você trafegar com $30 \%$ desses doentes anticoagulados, outra coisa é trafegar com $100 \%$ deles coagulados; nós tivemos problemas com sangramento, todo mundo tem. Foi um prazer o comentário do Dr. Salerno. Sei que a única pessoa, internacionalmente, que conhece o nosso trabaIho é o Dr. Salerno. Então, não há nenhuma vantagem, - Dr. Salerno é brasileiro, está no Canadá, é chefe de Serviço lá, e nos conhece; por isto é que ele conhece o nosso trabalho; de outra forma, jamais poderia ser conhecido fora do País. Nós sabemos que a válvula de Björk-Shiley foi descontinuada, nos Estados Unidos; eu não posso entrar nos detalhes; apenas diria que o comportamento da prótese de pericárdio bovino, aqui no Brasil, é este que mostrei, com toda honestidade; é lógico que a valvoplastia vai entrar, como entra no tratamento das coronárias. Eu queria dizer, ao Dr. Luiz Carlos, que isto aqui foi enfocado de maneira que fosse didática. A válvula de Starr-Edwards tem problemas; eu gostaria de dizer que, quando falei em mortalidade, ela não tem muito a ver com a válvula, aquela foi a mortalidade que eles apresentaram; a nossa é em torno de $60 \%$ e depende do grupo de doentes que estiver trabaIhando; agora, quanto a niveis de complicações, foi um dado que encontrei na literatura, que permitia fazer essa comparação; é recente e é de gente séria; de qualquer forma, quero dizer que, quando está livre de complicaçōes, estāo incluidos aqueles doentes que tiveram hemorragia; os doentes que estão tomando anticoagulante é que têm hemorragias; aquilo foi uma complicação, também decorrente da prótese que ele tem e pela qual ele deve usar anticoagulante. Agradeço os comentários e agradeço, também, à presidência da mesa, pela oportunidade de ter apresentado este trabalho. Obrigado. 